\title{
Damping analysis of cylindrical composite structures with enhanced viscoelastic properties
}

Kliem, Mathias; Høgsberg, Jan Becker; Vanwalleghem, Joachim ; Filippatos, Angelos ; Hoschützky, Stefan ; Fotsing, Edith-Roland ; Berggreen, Christian

\section{Published in:}

Applied Composite Materials

Link to article, DOI:

10.1007/s10443-018-9684-2

Publication date:

2019

Document Version

Peer reviewed version

Link back to DTU Orbit

Citation (APA):

Kliem, M., Høgsberg, J. B., Vanwalleghem, J., Filippatos, A., Hoschützky, S., Fotsing, E-R., \& Berggreen, C. (2019). Damping analysis of cylindrical composite structures with enhanced viscoelastic properties. Applied Composite Materials, 26(1), 85-113. https://doi.org/10.1007/s10443-018-9684-2

\section{General rights}

Copyright and moral rights for the publications made accessible in the public portal are retained by the authors and/or other copyright owners and it is a condition of accessing publications that users recognise and abide by the legal requirements associated with these rights.

- Users may download and print one copy of any publication from the public portal for the purpose of private study or research.

- You may not further distribute the material or use it for any profit-making activity or commercial gain

- You may freely distribute the URL identifying the publication in the public portal 


\title{
Damping analysis of cylindrical composite structures with enhanced viscoelastic properties
}

\author{
Mathias Kliem ${ }^{*}$, Jan Høgsberg ${ }^{1}$, Joachim Vanwalleghem² ${ }^{2}$, Angelos Filippatos ${ }^{3}$, Stefan \\ Hoschützky $^{4}$, Edith-Roland Fotsing ${ }^{5}$, Christian Berggreen ${ }^{1}$. \\ ${ }^{1}$ Department of Mechanical Engineering, Technical University of Denmark, Lyngby, Denmark \\ ${ }^{2}$ Department of Materials Science and Engineering, Ghent University, Belgium \\ ${ }^{3}$ Institute of Lightweight Engineering and Polymer Technology, Technische Universität Dresden, Germany \\ ${ }^{4}$ Leichtbau-Zentrum Sachsen GmbH, Dresden, Germany \\ ${ }^{5}$ Department of Mechanical Engineering, Polytechnique Montréal, Canada
}

\begin{abstract}
Constrained layer damping treatments are widely used in mechanical structures to damp acoustic noise and mechanical vibrations. A viscoelastic layer is thereby applied to a structure and covered by a stiff constraining layer. When the structure vibrates in a bending mode, the viscoelastic layer is forced to deform in shear mode. Thus, the vibration energy is dissipated as low grade frictional heat. This paper documents the efficiency of passive constrained layer damping treatments for low frequency vibrations of cylindrical composite specimens made of glass fibre-reinforced plastics. Different cross section geometries with shear webs have been investigated in order to study a beneficial effect on the damping characteristics of the cylinder. The viscoelastic damping layers are placed at different locations within the composite cylinder e.g. circumferential and along the neutral plane to evaluate the location-dependent efficiency of constrained layer damping treatments. The results of the study provide a thorough understanding of constrained layer damping treatments and an improved damping design of the cylindrical composite structure. The highest damping is achieved when placing the damping layer in the neutral plane perpendicular to the bending load. The results are based on free decay tests of the composite structure.
\end{abstract}

Keywords: Composite structure; Passive damping treatment; Filament winding; Vibration analysis; Function integration

\footnotetext{
${ }^{*}$ Corresponding author: mkliem@mek.dtu.dk
} 


\section{Introduction}

Glass fibre-reinforced plastics (GFRP) are well suited for use in high voltage applications, such as insulators or overhead transmission pylons, due to the inherent non-conductivity of the raw material. This enables a rigid attachment of overhead transmission lines to the cross arm of each composite pylon, resulting in an increased dynamic interaction. Induced vibrations, such as from the severe cable vibration phenomenon known as galloping, will therefore be directly transferred to the slender composite mast structure and may lead to catastrophic failure of the entire structure due to excessive vibration amplitudes at resonance [1]. These low-frequent galloping vibration amplitudes at frequencies between $0.5 \mathrm{~Hz}$ and $2 \mathrm{~Hz}$ depend e.g. on the cable vibration mode, the cable tension and the span length [2] and can be reduced by designing the composite power pylon to act as a supportive damper. By introducing passive damping supplements, such as the constrained layer damping (CLD) treatment, the energy dissipation in the composite structure may significantly be increased due to the shear deformation of the integrated viscoelastic material (VEM) damping layer located between two stiff layers: layer 1 - host structure and layer 2 - constraining layer (CL) [3].

In contrast to tuned resonance dampers, such as tuned mass dampers or tuned liquid dampers configured to damp a certain frequency, the passive CLD treatment may be suitable to damp galloping vibrations within a larger frequency range [4]. However, the additional weight of the VEM and the CL may reduce the stiffness and consequently the natural frequency of a structure, when keeping the overall dimensions constant. The trend in the design of passive CLD treatments for lightweight structures is therefore increasing towards damping patches instead of a full damping layer coverage [5]. The VEM-patches are typically located at areas with high shear deformation, which is usually close to the nodes of a mode shape. The added weight of a passive CLD treatment can be reduced by $50 \%$ with respect to full layer damping, while maintaining the overall damping performance [6]. However, many possible locations with high shear deformation exist along a power pylon arm because of the variety of attached conductor line bundles - each with the potential to vibrate by itself or in combination with other cables or cable bundles. Due to the wide range of resulting vibration scenarios of a composite cross arm, the investigation of VEM damping patches is therefore not part of the paper, and has to be addressed in future investigations.

The focus in this paper will be on a full coverage of VEM damping layers in the length wise direction of the generic composite cylinder instead, as the effect of additionally implemented structural elements such as stiffening web on the damping behaviour is investigated. An optimization process regarding a reduction of the amount of applied VEM within a damping-enhanced cross-sectional design concept may be an interesting topic to be investigated further. The cross sectional shape of the structure will also have a great impact on the efficiency of CLD treatments. The proportion of the shear deformed VEM area which is further away from the neutral axis is higher for rectangular cross sections compared to equivalent circular cross sections and will therefore result in better damping [7]. Despite the obvious advantages of rectangular cross sections with regard to damping, the design of the power pylon arm and tower is restricted to a cylindrical outer geometry by the designer. However, no design restrictions are defined for the inside of the composite cylinder, providing a design flexibility with respect to the application of passive CLD treatments within the pylon arm and tower structure $[8,9]$.

To the best knowledge of the authors, a comprehensive, experimental and numerical analysis of passive CLD treatments with regard to various positions along the cross section of hollow composite cylinders has not been 
conducted yet. Therefore, different structural damping-design configurations based on various CLD treatment locations are investigated for eight generic, hollow composite cylinders. The resulting energy dissipation during flexural vibrations is experimentally investigated by analysing the free vibration decay and calculating the loss factor $\eta$ for the first bending mode.

Furthermore, the experimental results are used to validate a numerical damping analysis based on the modal strain-energy approach, taking the fibre direction material properties into account [10, 11, 12, 13]. A script written in Python enables the calculation of the system modal damping of the composite structure using the finite element analysis (FEA) software package ABAQUS [14].

\section{Aim and outline of the paper}

The aim of the paper is to provide a method for the dynamic design of generic composite cylinders with maximum vibration damping. Different cross sectional designs are investigated in order to evaluate the location-dependent damping enhancement by CLD treatments. The presented results and properties may be considered in the dynamic design of the next generation of composite power pylon arms.

The damping enhancement of generic composite cylinders is achieved by using viscoelastic damping layers at various locations in the cross section. Eight generic cross section designs are presented and evaluated with regard to its stiffness-weight ratio. Prototypes are manufactured using the filament winding technology and tested statically and dynamically with regard to bending stiffness and damping properties. The results are used to verify the numerical model for the modal damping prediction. Finally, the comparison of experimental and numerical results is presented and discussed.

\section{Design of the generic composite tube}

This section provides a detailed description of the design and manufacturing of the different generic composite tubes with and without implemented damping layers. The laminate design as well as the load assumptions are derived from the full-scale composite power pylon arm structure at a location close to the root-end.

\subsection{Composite power pylon structure}

The composite power pylon consists of a tubular column section, supporting a pair of cantilevered and tapered composite cylindrical arms at which three pairs of twin bundle conductor lines are directly attached on each arm (see Fig. 1). The composite arm structure is thereby designed for vertical and transverse bending loads in $\mathrm{x}$ and $\mathrm{y}$ directions due to the cables weight and common loads from climatic situations such as individual or combined ice and wind loading [16]. Furthermore, vibrating cables due to galloping will introduce dynamic bending loads to the power pylon arms. Based on an optimised, stiffness driven design of the power pylon arms, the laminate thickness gradually decreases from the thick-walled layup configuration at the root-end section to the thin-walled shell-like zone at the tip of the arm.

The power pylon structure will be designed with maximal stiffness, preventing any resonant vibrations of the pylon at typical galloping frequencies. However, any change in cable tension and span length requires a re-examination of the vibration behaviour of the cable-pylon-system and, if necessary, an individual stiffness 
Table 1: Geometric and stacking properties of the generic composite tube.

\begin{tabular}{cc}
\hline Parameter & Layup and Dimensions \\
\hline Free specimen length $l$ & $950 \pm 5 \mathrm{~mm}$ \\
Constant inner diameter $D_{i}$ & $79.0 \mathrm{~mm}$ \\
Wall thickness 'host structure' & $4.0 \mathrm{~mm}$ \\
Host structure layup & {$\left[ \pm 45^{\circ}, \pm 45^{\circ}, \pm 10^{\circ}, \pm 45^{\circ}\right]$} \\
Constraining layer $(\mathrm{CL})$ layup & {$\left[ \pm 10^{\circ}\right]$} \\
Layer thickness GFRP $\left[ \pm 45^{\circ}\right]$ & $0.88 \mathrm{~mm}$ \\
Layer thickness GFRP $\left[ \pm 10^{\circ}\right]$ & $1.00 \mathrm{~mm}($ segment $)-1.35 \mathrm{~mm}$ (circular) \\
Layer thickness VEM & $0.58 \mathrm{~mm}$ \\
Spacer plate thickness & $3.0 \mathrm{~mm}$ \\
\hline
\end{tabular}

adjustment of the power pylon. At the same time, adequate damping of the composite structure is required in order to minimize vibrational amplitudes of the cables and the cross arm due to galloping and thereby prevent severe structural damage.

Tuned resonance dampers are not feasible damper solutions, as they are adjusted to damp only a single frequency instead of typical galloping frequencies in a range between $0.5 \mathrm{~Hz}$ and $2 \mathrm{~Hz}$. Furthermore, high electro-magnetic fields do not allow the use of active controlled damping devices.

Instead, non-conductive CLD treatments are well suited for the application in high-voltage power pylons as these are low cost, robust, reliable and maintenance-free structural vibration control methods [17]. However, the application of CLD treatments may considerably reduce the advantage of a lightweight design, defined by the stiffness-weight-ratio, when restricting the geometry [18]. Either the static stiffness of a structure is reduced

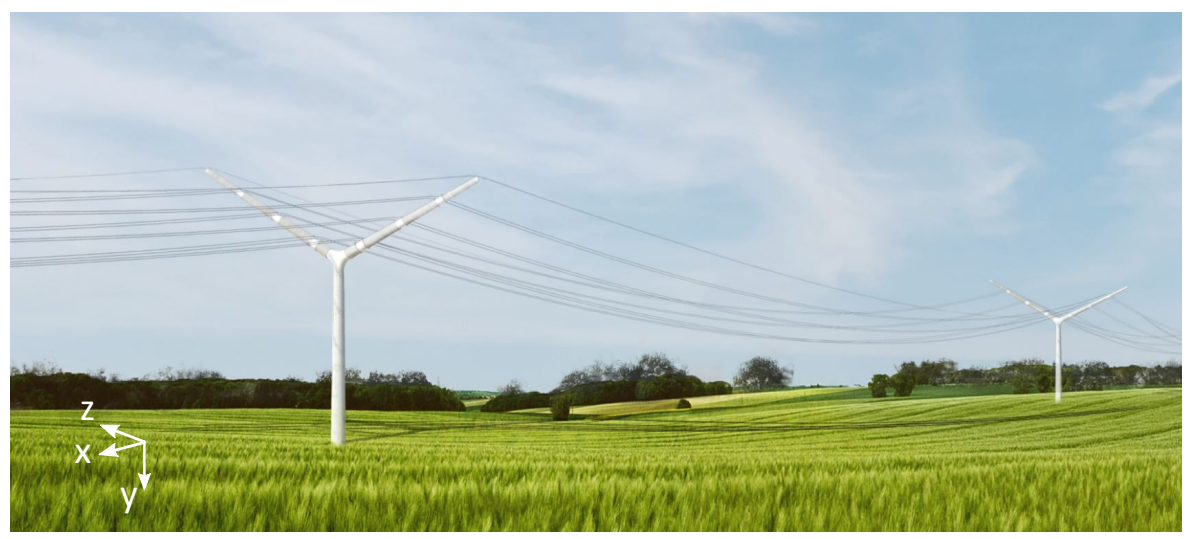

Figure 1: Composite power pylon with directly attached overhead transmission line bundles in the global coordinate system [15]. 
while keeping the weight constant or vice versa.

In this work, the design focus is on maximizing the vibration damping of the composite structure, while keeping the natural frequencies constant. The outer dimension should therefore remain unchanged, so that a potential reinforcement is applied to the inside of the structure. The increase in weight is tolerated and only of minor importance, as the power pylon is considered mainly a static structure not excited at its own resonance frequency. The appearance of galloping overhead transmission lines causing the power pylon to vibrate is a rare but dangerous incident and is therefore considered as an important design criteria for power pylons [19]. The trade-off between an increase in weight and the related increase in costs with regard to material, manufacturing, transportation and installation must also be considered.

\subsection{Generic composite cylinder with passive damping treatments}

Based on the design of the composite power pylon cross arm, generic composite specimens are developed in the scale of 1:10 with respect to dimensions and stacking sequence of the laminate. The generic composite cylinders represent the cross sectional properties of the cross arm at a position close to the root end section, assuming loading conditions that are free of clamping effects. For reasons of simplicity and comparability, all generic composite specimens are non-tapered, cylindrical and hollow with constant laminate properties along the entire length. The dimensions and layups are specified in Tab. 1.

The efficiency of a damping layer strongly depends on its shear deformation and therefore on the position in the host structure. The VEM is preferably located far from the neutral plane for structures undergoing flexural vibrations, due to the maximum flexural deformation [20].

Alternatively, the positioning of the VEM layer close to the neutral plane also leads to high shear strains in the damping material due to the presence of maximum shear stresses [21]. The damping is thereby most effective when two VEM layers are positioned symmetrically and close to the neutral plane during bending, separated by a stiff mid plane laminate of the host structure [22,11]. As the design flexibility of CLD treatments is very limited for hollow cylinder structures with regard to its position, a laminated shear web may therefore be introduced into the neutral plane in order to provide a stiff structure for a potential CLD treatment close to the neutral plane (see Fig. 2). The VEM damping layers can then be applied symmetrically to both sides of the neutral plane, representing the most efficient damping scenario described above.

It is assumed that the highest damping performance will be achieved when flexing in the direction perpendicular to the CLD-treated shear web plane. The ribs are positioned in one or two directions in order to possibly damp vibrations of the power pylon arm in $\mathrm{x}$ and $\mid$ or $\mathrm{y}$ direction of the global coordinate system (see Fig. 1), caused by the directly mounted overhead transmission line bundles, which are vibrating due to galloping. The resulting loading direction at the pylon arm thereby depends on a symmetric or asymmetric cable vibration mode [23]. The application of VEM damping layers along a the circumference in accordance to the above mentioned positions with maximum shear deformation consequently leads to the following damping layer configurations for the generic composite cylinder: Eight cross-sectional design concepts were investigated (design A to I) in order to evaluate the efficiency of various VEM layer positions along the cross section. An overview of the eight designs is presented in Fig. 2.

The load carrying laminate thickness (section I, II) with $\mathrm{t}=4.0 \mathrm{~mm}$ remains constant for all design concepts, due 


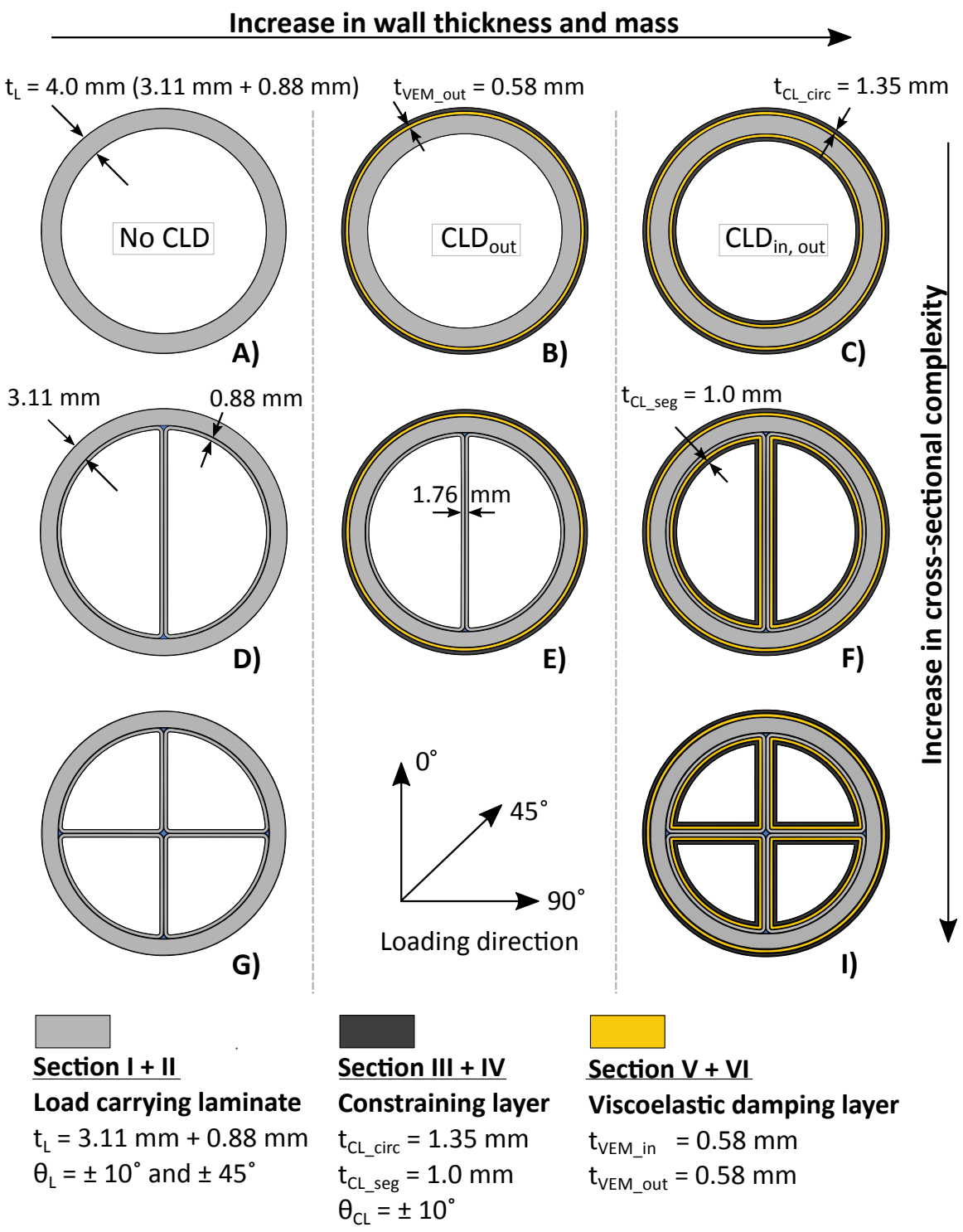

Figure 2: Overview on the different cross-sectional designs with details to the stacking sequence and loading direction (not drawn to scale).

to structural requirements, explained in detail below. The application of viscoelastic damping layers (section $\mathrm{V}$ and VI) on the in- and outside in combination with stiff constraining layers (section III and IV) will generate the CLD treatment. An integration of VEM damping layers into the load carrying laminate to further increase the damping is not considered in the present paper, as a safe load introduction of the overhead transmission lines into the cross arm is strongly required over the structural lifetime of 100 years. However, interleaved damping layers may considerably weaken the load carrying laminate so that a reliable load introduction may not be obtained. The alternative approach to reinforce the load introduction areas along the slender composite cross arm in a subsequent step is not as trivial in a filament winding process of a near neat shaped cylindrical structure, and may therefore not considered any further. For the sake of simplicity, a constant wall thickness for all generic composite cylinders is assumed in the present paper for evaluating the effect of various damping layer 
configurations on the overall damping behaviour. It is expected that the application of stiff constraining layers may increase the stiffness and vibration behaviour. In order to fairly compare the different design concepts with regard to damping and vibration frequency, the specimens are grouped based on the level of applied CLD treatments (No CLD, CLD out,$C_{\text {in,out }}$ ). However, this approach is a trade-off between the implementation of structural requirements and scientific evaluation of damping enhancement treatments. Each cross-sectional designs may be assessed in terms of an 'increase in cross-sectional complexity' and 'increase in weight and wall thickness'. As the complexity of the cross-sectional design is directly related to an expensive, costly and time-consuming manufacturing process, a concept with high complexity (concept G or I) may be chosen when a high damping in combination with a high stiffness-weight ratio is required. In contrast, the application of CLD treatments to specimens with a low cross-sectional complexity leads a considerable increase in wall thickness and weight, when keeping the natural frequency constant (concept A to C).

However, a grouping with respect to an 'increase in cross-sectional complexity' is described in detail as follows: In the first group (A to C), the VEM layer is applied only circumferential on the outside (B) or on the in- and outside (C), covered by a stiff CL, respectively. The CLD treatment applied on the inside of the structure is assumed to be less effective than a CLD treatment on the outside, due to a reduced distance from the neutral plane and thus smaller flexural deformations. However, each CL represents a thin and individual laminate, coupled to the host structure only by the VEM damping layer. When the host structure flexes, the additional laminate deforms, introducing shear strains in the VEM and thereby damping. The laminate of the host structure consists of eight layers, each defined by a fibre direction $\varphi$ with respect to the axial direction $\mathrm{z}$ in the global coordinate system of the cylinder $\left[ \pm 45^{\circ}, \pm 45^{\circ}, \pm 10^{\circ}, \pm 45^{\circ}\right.$ ] (see Fig. 1). The presented fibre orientations of the generic composite cylinder are equivalent to stacking sequence of the composite cross arm, earlier defined by the designer.

In the second group (D to F), a shear web made of two symmetrical GF-EP composite layers with a material orientation of $\varphi= \pm 45^{\circ}$ is introduced, representing the inner layer of the host structure laminate. A fibre direction of $\varphi= \pm 45^{\circ}$ was chosen since mainly shear stresses occur during bending and a reliable manufacturability of that fibre angle is feasible by filament winding. The remaining $\pm 45^{\circ}, \pm 10^{\circ}$ and $\pm 45^{\circ}$ layers of the host structure are of cylindrical shape. The layup and thickness of the host structure is thereby kept constant for all design concepts A to I. For concept E, the CLD treatment is only added to the outside of the structure. In order to further increase the damping of the generic composite structure, VEM damping layers are also placed close to the neutral plane with its maximum shear stresses. Thereby, two individual and hollow half cylinders are generated by the inner CL.

In the third group (design G and I), two perpendicular shear webs are introduced the same way as described for the one-web design concept $\mathrm{D}$ to $\mathrm{F}$, resulting in four individual quarter cylinders. A rotation of the shear web with respect to the loading direction leads to a variation in static stiffness, natural frequency and damping. Therefore, the two significant loading directions $0^{\circ}$ and $90^{\circ}$ with regard to the shear web plane will be investigated for design concept D, E and F. The composite cylinders of concept G and I are only loaded in $45^{\circ}$, as a loading in $0^{\circ}$ and $90^{\circ}$ is equivalent to the conditions investigated for the design concepts $\mathrm{D}, \mathrm{E}$ and $\mathrm{F}$. The concept and the loading is specified in its notation, where the cross sectional design concept is defined by a letter (A to I) and the loading direction $\left(0^{\circ}, 45^{\circ}\right.$ or $\left.90^{\circ}\right)$ is stated by a number (e.g. I.45). 


\subsection{Materials}

The materials used for manufacturing the generic composites cylinders are considered to be the same as for the composite power pylon arms. A glass fibre (GF) roving EC17-2400-352 with 2400 tex and a sizing suitable for epoxy and vinyl-ester from PD Fibre Glass was used in combination with the PRIME 20 epoxy (EP) resin and the slow hardener from Gurit [24, 14]. The static material properties of GF-EP were determined based on a planar unidirectional (UD) composite plate, made up of a UD GF fabric with an area weight of $475 \mathrm{~g} / \mathrm{m}^{2}$ (incl. $35 \mathrm{~g} / \mathrm{m}^{2}$ of a chopped strand mat) and the Prime 20 Epoxy [14]. The static GF-EP properties at room temperature are given as follows: $\mathrm{E}_{11}=27.6 \mathrm{GPa}, \mathrm{E}_{22}=5.3 \mathrm{GPa}, \mathrm{G}_{12}=2.0 \mathrm{GPa}, \nu_{12}=0.345$ and $\rho=1.79 \mathrm{~g} / \mathrm{cm}^{3}$ [14]. The particular polyurethane (PU) material DYAD 601 from Soundcoat with a thickness of $0.58 \mathrm{~mm}$ was selected as VEM damping layer for the damping investigation of the generic composite cylinder, due to its optimised damping performance at temperatures prone for galloping vibrations around $0{ }^{\circ} \mathrm{C}$. However, any other VEM may be selected, depending on the required damping performance. The surface of the elastomer was initially coated with a B-Flex epoxy formulation, assuring a high adhesive quality [25].

PU materials are the most commonly used VEM's for vibration control. However, these materials exhibit frequency and temperature dependent material properties with an optimal damping characteristics of a narrow frequency and temperature range [26]. The dynamic stiffness and damping properties of DYAD 601 are therefore discussed in more detail in section 5.1. However, the Poisson's ratio is assumed to be constant with $\nu=0.49$ for the investigated frequency and temperature range [27]. The density of DYAD 601 was determined as $\rho=1.04 \mathrm{~g} / \mathrm{cm}^{3}$.

\subsection{Manufacturing of test specimens}

The damping behaviour of GF-EP was determined at coupon and structural level with two different sets of GF-EP specimens: 1) Unidirectional (UD) composite coupons were used to characterise the fibre direction dependent damping behaviour. 2) Various composite cylinders with different cross section designs were manufactured by filament winding in order to demonstrate the potential of VEM damping layers with regard to a vibrating power pylon arm.

\subsubsection{Manufacturing of coupons}

The same coupon specimens, used for a previous damping investigation [14], were dynamically tested to characterise the fibre direction damping at room temperature between $20 \mathrm{~Hz}$ and $60 \mathrm{~Hz}$. The first natural frequency of the investigated composite cylinders lies within this frequency range. The static and dynamic properties of the two different sets of specimens are thereby assumed to be of the same order of magnitude, due to the use of similar UD GF materials. A detailed description of the generic composite cylinder manufacturing is presented in the following. 


\subsubsection{Manufacturing of generic composite cylinders}

Filament winding is a well suited manufacturing process for cylindrical composite parts with a constant layup throughout the whole specimen due to its high efficient, automated and low cost fabrication characteristics [28]. Although a typical range of fibre layup angles for filament winding is between $20^{\circ}$ and $85^{\circ}$, local reinforcement with very low winding angles can be implemented during the manufacturing process by the use of pins for fibre redirection at each end of the mandrel [29]. This layup modification might be used to reinforce the compression side of slender composite power pylon arm structures subjected to bending loads in order to prevent buckling. A segmentable aluminium mandrel was designed and CNC-milled in order to manufacture the different crosssectional designs using a wet filament winding process (see Fig. 3).

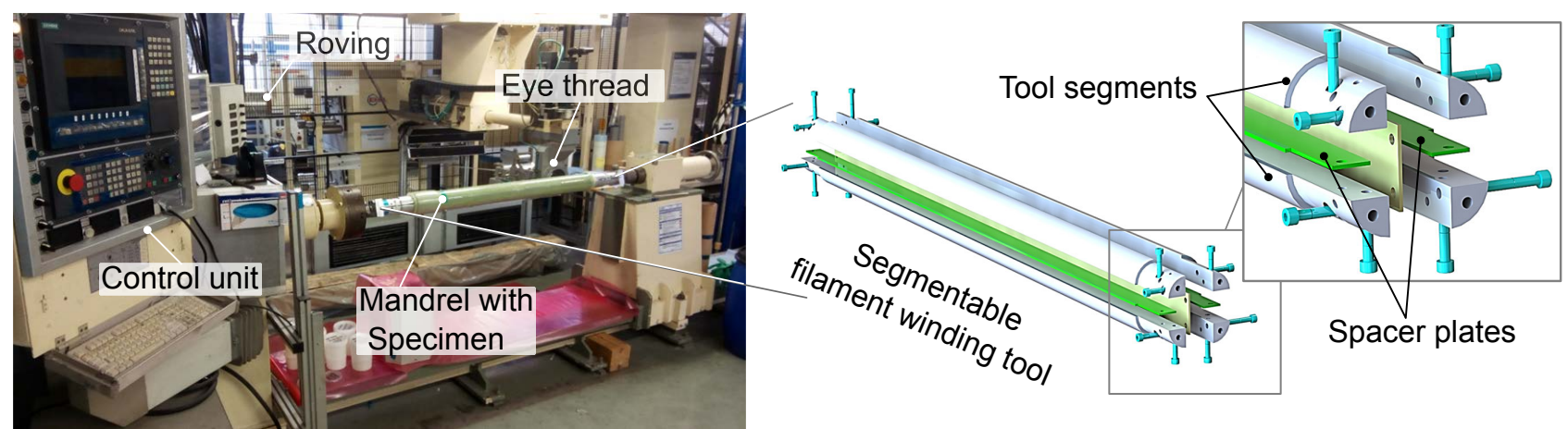

Figure 3: Manufacturing of the generic tubular composite structure using a filament winding machine and the tool segments.

Thereby, a wet GF, impregnated by a resin bath prior to the placement process, was positioned and cured on the mandrel (tool). By either winding on a single tool segment, a 'two-segment assembly' or a 'four-segment assembly', generic composite specimens consisting of two shear webs (design concepts G to I), one shear web (design concepts D to F) or no shear web (design concepts A to C) may be manufactured. In case of a composite cylinder with only one shear web and no VEM damping layer (design concept D), the manufacturing process consists of five stages:

1. Assembly of two tool segments and a $3 \mathrm{~mm}$ thick spacer plate, forming a cylinder half,

2. Filament winding of the first layer of the host structure laminate with $\varphi= \pm 45^{\circ}$ on the two cylinder halves respectively (see Tab. 1),

3. Mounting of the two cylinder halves to a 'two-segment assembly',

4. Finalizing the winding process with the three remaining host structure layers with $\varphi= \pm 45^{\circ}, \pm 10^{\circ}$, and $\pm 45^{\circ}$,

5. Thickening the end section for clamping, curing and mandrel removal.

The manufacturing process for composite cylinders without shear webs (design concept A to C) significantly simplifies, as the mounting procedure described in step 3.) vanishes. The fully assembled, cylindrical mandrel 
with its $3 \mathrm{~mm}$ thick spacer plates, representing the shear webs, may be used directly. For design concepts with shear webs (concept D to I), the shear webs vary in thickness, depending on the presence of VEM damping layers (shear web thickness of concept D: $1.76 \mathrm{~mm}$ | concept F: $4.9 \mathrm{~mm}$ ). This causes an ovalization of the cross section, which may lead to a slight change in bending stiffness compared to its equivalent circular concept (concept A, B or C). Therefore, the ovalization of the cross section was considered in the numerical model in order to fairly compare the different damping designs.

Dependent on the cross-sectional design (concept B, C, E, F or I), the VEM damping layer was applied by wrapping a $70 \mathrm{~mm}$ wide stripe of DYAD 601 helically and gap-free on the wet GF-EP structure. The final layup was cured under constant rotation in a climate chamber for 10 hours at $70^{\circ} \mathrm{C}$ before pulling out the mandrel. The end sections were thickened and subsequently lathed to an outer diameter of $D_{o} \approx 100 \mathrm{~mm}$ in order to provide constant clamping conditions. The reinforcement is about $100 \mathrm{~mm}$ long and made of $\mathrm{n}$ GF-EP layers, each with a fibre direction of $\varphi= \pm 85^{\circ}$, as shown in Fig. 4.

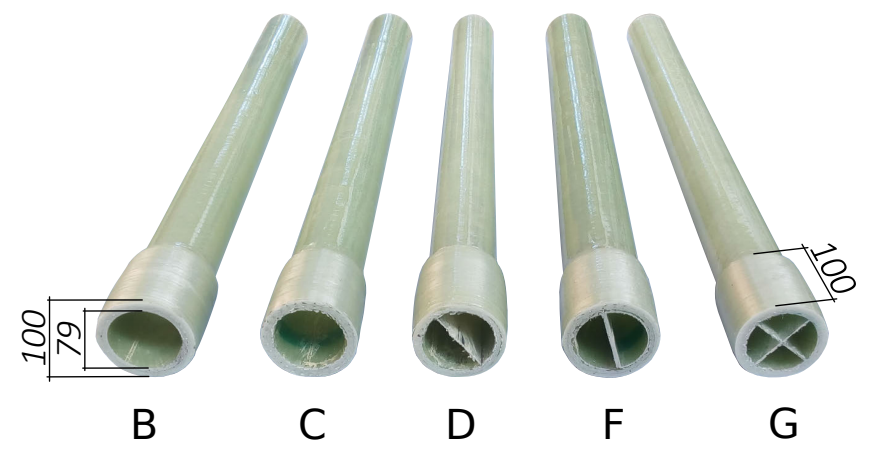

Figure 4: Selection of different manufactured cylindrical composite design concepts, where the inner area is visible.

Due to the constant outer diameter of the mandrel with $\mathrm{D}_{M}=79 \mathrm{~mm}$, the outer diameter of the cylindrical composite structure increases by applying CLD treatments, when keeping the laminate thickness of the host structure constant (e.g. concept A to C). This violates the initial design restriction (see section 3.1) because such restrictions are simply hard to realize with a single mandrel. Therefore, the results will be appropriately normalized in order to ensure comparability between the different concepts (see section 3.2).

The weight and fibre volume content of the manufactured specimens with regard to their different cross-sectional design concepts are listed in Tab. 2. The fibre volume content was calculated by the known total weight of the structure, the amount of the used fibre (and VEM material) as well as the related densities.

In Fig. 5 the inner and the outer damping layer distribution is shown for the cross-sectional design concept I.45 by a schematic and a realistic micro-section.

\section{Numerical damping calculation}

The numerical prediction of the modal loss factor of a vibrating composite cylinder is based on the modal strain-energy approach [30], manually implemented into the commercially available finite element (FE) software 
Table 2: Design-related properties of the different generic composite cylinders.

\begin{tabular}{cccccccccc}
\hline & \multicolumn{1}{c}{ Cross-sectional design } \\
Parameter & A & B & C & D & E & F & G & I \\
& & & & & & & & \\
Mass [kg] & 2.04 & 3.00 & 3.69 & 2.32 & 3.36 & 4.67 & 2.56 & 5.30 \\
Fibre volume content [\%] & 51.0 & 45.6 & 51.3 & 50.4 & 53.4 & 48.4 & 48.8 & 42.4 \\
\hline
\end{tabular}

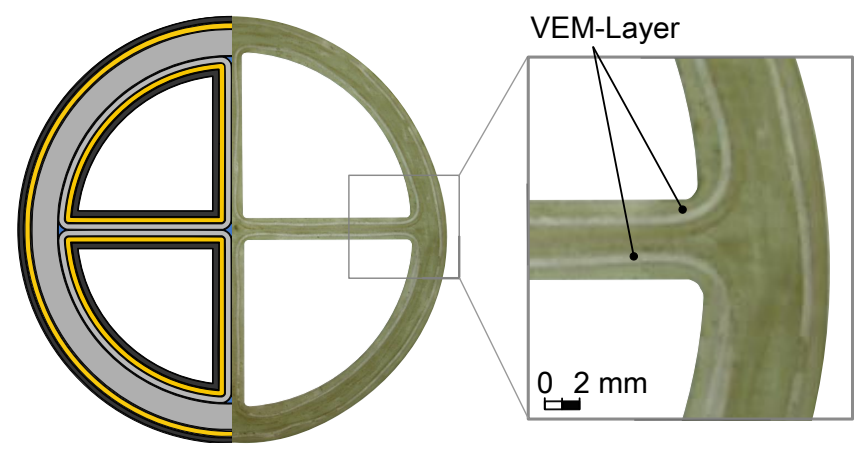

Figure 5: Distribution of the VEM for the cross-sectional design concept I.45 (left) and zoom into the interesting area (right).

ABAQUS $[31,14]$. The loss factor $\eta$ can be calculated as

$$
\eta=\frac{1}{2 \pi} \frac{\Delta U}{U} .
$$

The dissipated energy and the stored energy with regard to a single oscillation is represented by $\Delta U$ and $U$, respectively. The energies are fibre direction dependent, due to the orthotropic nature of composite materials. The element-wise calculation of $\Delta U$ and $U$ is therefore based on the local material coordinate system $(i, j=1$, $2,3)[11]$ by

$$
U_{i j}^{[m]}=\frac{1}{2} \sigma_{i j}^{[m]} \epsilon_{i j}^{[m]} V^{[m]}
$$

with $\sigma_{i j}^{[m]}, \epsilon_{i j}^{[m]}$ and $V^{[m]}$ representing the stress and strain components as well as the $m$-th element volume, respectively. The modal loss factor for the first natural frequency $\eta_{1}$ of a composite structure with $N$ layers, each with a total number of elements $N_{e}$, may then be computed by

$$
\eta_{1}=\frac{\sum_{m=1}^{N_{e}} \sum_{k=1}^{N} \sum_{i=1}^{3} \sum_{j=1}^{3}\left(\eta_{i j} U_{i j}^{[m](k)}\right)}{\sum_{m=1}^{N_{e}} \sum_{k=1}^{N} \sum_{i=1}^{3} \sum_{j=1}^{3}\left(U_{i j}^{[m](k)}\right)} .
$$

The finite element (FE) model of the generic composite cylinder is composed of fully integrated, 8-node hexahedron elements. Adjacent layers with equal thickness were section-wise modelled using the composite layup 
module provided by ABAQUS [32]. The results of the numerical damping prediction and the experimental decay test are compared in order to verify the FE model.

\section{$5 \quad$ Experimental test setup}

This section provides a detailed description of the procedures used to experimentally determine the dynamic mechanical properties of the VEM damping layer, the unidirectional (UD) composite coupons and the generic composite cylinder at room temperature. The Dynamic Mechanical Thermal Analysis (DMTA) and the Vibrating Beam Test (VBT) were used to investigate the damping properties on the material and structural level. All experimental data sets are published and freely available [33].

\subsection{Dynamic mechanical analysis of viscoelastic material}

The Dynamic Mechanical Thermal Analyser (DMTA) used for the damping characterisation of the DYAD 601 samples was a Q800 from TA with shear sandwich clamps, as shown in Fig. 6.

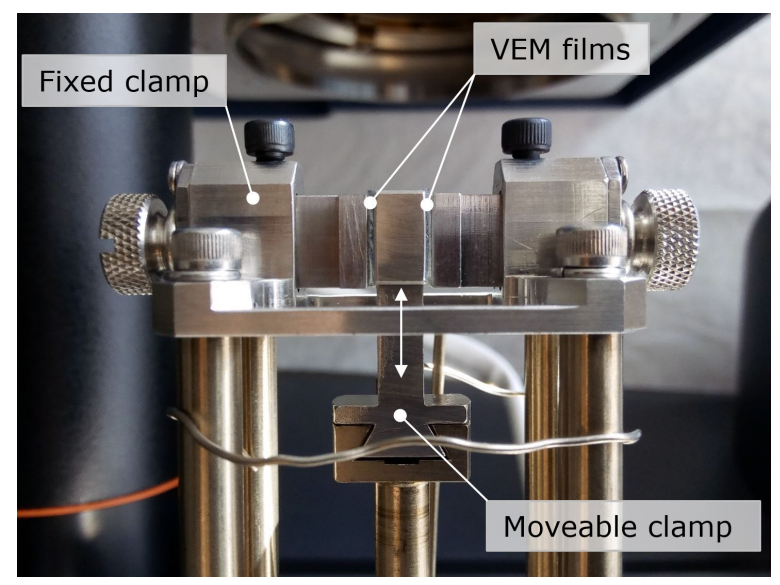

Figure 6: Clamped VEM films to analyse the shear damping by DMTA using the Q800 from TA.

The dynamic mechanical properties were analysed under two environmental conditions: I) conditions prone for cable galloping $\left(-20^{\circ}\right.$ and $0^{\circ} \mid$ from $0.5 \mathrm{~Hz}$ to $\left.2 \mathrm{~Hz}\right)$ and II) conditions for generic composite cylinder testing $\left(20^{\circ} \mid 50 \mathrm{~Hz}\right)$. The frequency dependent complex shear modulus $G^{*}$ of the VEM may be calculated by

$$
\left|G^{*}(f)\right|=\sqrt{\left[G^{\prime}(f)\right]^{2}+\left[G^{\prime \prime}(f)\right]^{2}} .
$$

where $G^{\prime}(f)$ and $G^{\prime \prime}(f)$ represent the frequency dependent shear storage and shear loss modulus, respectively [34].

All DMTA shear tests have been performed within the linear viscoelastic range of the elastomer, so that constant material properties can be assumed. An approximately linear viscoelastic behaviour of DYAD 601 was quasistatically determined for shear strains below $1.5 \%$ with regard to the three different test temperatures $-20^{\circ} \mathrm{C}$, $0{ }^{\circ} \mathrm{C}$ and $20^{\circ} \mathrm{C}$ (see Fig. 7).

The dynamic characterisation of DYAD 601 was therefore carried out at strains well below 1.5\% (see section 
5.1). The calculation of the frequency dependent complex E-modulus $E^{*}$ of elastomer materials such the DYAD 601 may be calculated by

$$
E^{*}(f)=3 G^{*}(f)
$$

assuming incompressibility $(\nu=0.5)[35]$.

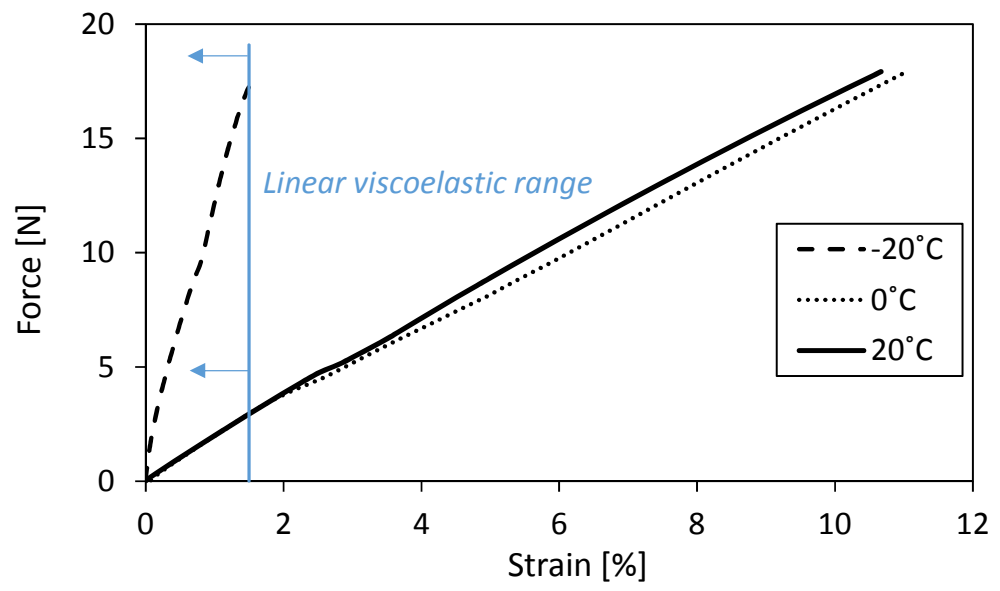

Figure 7: Strain sweep of DYAD 601 for the relevant temperatures: $-20^{\circ} \mathrm{C}, 0{ }^{\circ} \mathrm{C}$ and $20^{\circ} \mathrm{C}$.

\subsection{Damping analysis of unidirectional GFRP coupons}

Due to the relatively low damping of fibre-reinforced thermoset materials at room temperature compared to viscoelastic elastomers, the dynamic moduli $E^{*}$ and $G^{*}$ for GF-EP is considered to be constant within the studied frequency range and therefore assumed to be equivalent to the static moduli (see section 3.3) [36]. The fibre direction dependent damping properties were determined using the vibrating beam test method (VBT), which was successfully verified in a previous investigation [14]. An initial tip displacement of $5 \mathrm{~mm}$ was used for all investigated specimens. Furthermore, the free length of the vibrating coupon specimens were adjusted in order to determine the damping at different frequencies.

Two GF-EP specimens were tested per fibre direction without readjusting the clamped sample before repeating the measurement three times (six measurements in total per fibre direction and frequency). A logarithmic trend line was applied for each fibre direction in order to visualize the trend of the frequency dependent damping.

\subsection{Damping analysis of generic composite cylinders}

All cylindrical composite specimens were provided with an end-sectional outer diameter of $D_{o}=100 \mathrm{~mm}$ for constant clamping conditions. Metallic inserts with circular, semicircular or quarter-circular cross sections were pressed into each end section of the composite specimens in order to prevent the cross section to become oval during clamping and loading. The reinforced end of the cylinder was fixed to a strong table by two pairs of steel half shells, screwed together with four screws, each with a tightening torque of $200 \mathrm{Nm}$. The half shells were 
designed with an interference fit with regard to the outer diameter of the composite cylinder, in order to obtain constant clamping conditions by press fit. The clamping half shells were supported by four bracing elements in order to further stiffen the clamping area.

The static stiffness was determined by applying a bending load with a hydraulic lifting device. The signal was logged using a $3 \mathrm{kN}$ load cell in combination with an analog input module NI 9237 from National Instruments. In contrast, the excitation of the flexural vibration for the dynamic investigation of the composite cylinder occurred by impulse. The cylinder was therefore hit by a rubber block mounted on a bracket in vertical direction. The test setup is shown in Fig. 8.

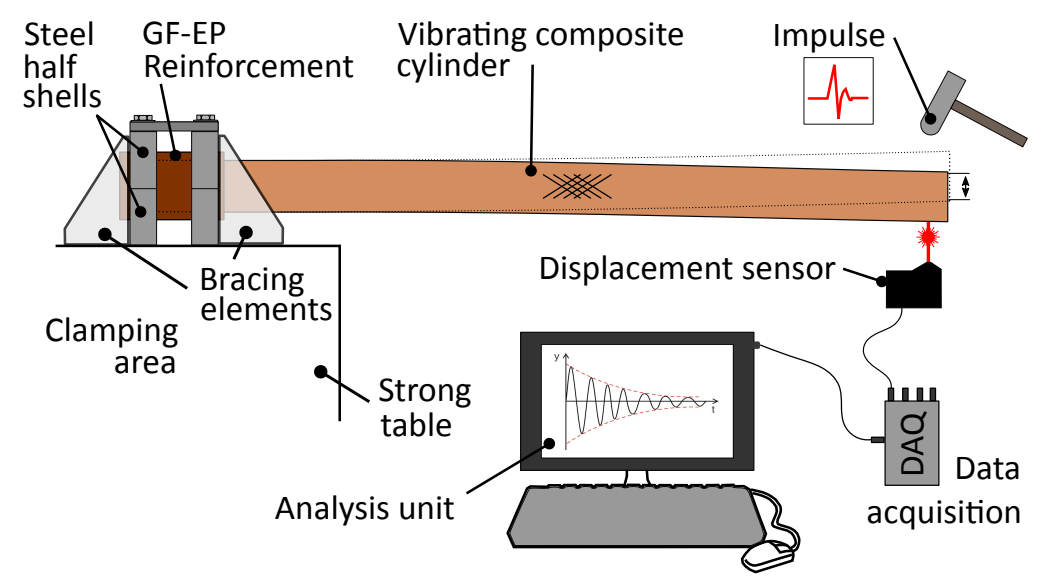

Figure 8: Schematic free vibration test rig for composite cylinders.

The resulting vibration amplitudes were kept below $0.8 \%$ of the free cylinder length of $l=960 \mathrm{~mm} \pm 3 \mathrm{~mm}$, depending on the bending stiffness of each composite structure. It is assumed that air damping is constant within this range. A laser displacement sensor optoNCDT 1402 from Micro-Epsilon with a sampling frequency of $2000 \mathrm{~Hz}$ together with an analog input module NI 9215 from National Instruments were used to log the declining sine curve of the freely vibrating cylinder. The accuracy of the measurement parameters were verified in a previous damping investigation [14].

It is assumed that mainly the first mode dominates the dynamic behaviour of the structure. The first 10 periods were neglected in order for activated higher modes to die out. Any influence from other modes are thereby neglected. An exponential curve may be fitted as an envelope $g(t)$ on the response signal, which can be described for the first mode as

$$
g(t)=X_{0} e^{-\zeta \omega_{1} t} .
$$

The first natural angular frequency, the damping ratio and the initial displacement are thereby represented by $\omega_{1}, \zeta$ and $X_{0}$ respectively [37]. The loss factor of the vibrating composite structure may be calculated by

$$
\eta \approx 2 \zeta
$$

In order to evaluate the influence of the clamping, which is typically leading to a frequency dependent viscous behaviour, dead weights were mounted to the tip of the cylinder. The resulting variation of the first natural 
frequency $f_{1}=\omega_{1} / 2 \pi$ in the range between $20 \mathrm{~Hz}$ and $60 \mathrm{~Hz}$ is not supposed to strongly effect the damping of the composite structure. Each composite cylinder, representing a specific cross-sectional design, was tested without readjusting the clamped specimen before repeating the measurement at least 12 times.

\section{Results and Discussion}

The dynamic mechanical properties of the composite structure as well as its individual materials are presented, followed by the comparison with the numerical model.

\subsection{Dynamic properties on material level}

The cylindrical composite structures listed in Fig. 2 are composed of unidirectional GFRP layers with various orientation and to some extent with viscoelastic damping layers. In order to predict the modal loss factor $\eta_{1}$ of the vibrating composite structure by the modal strain-energy method, the damping of each individual material involved must be known. The dynamic mechanical properties of the VEM and the UD-GFRP have therefore been analysed at temperatures and frequencies of different environmental conditions.

\subsubsection{Viscoelastic material}

The loss factor as well as the storage and loss moduli of the VEM were investigated by DMTA at conditions close to structural testing of the composite cylinder $\left(20^{\circ} \mathrm{C}\right.$ and $\left.50 \mathrm{~Hz}\right)$ and conditions close to galloping $\left(-20^{\circ} \mathrm{C}\right.$ and $0{ }^{\circ} \mathrm{C}, 0.5 \mathrm{~Hz}, 1 \mathrm{~Hz}$ and $2 \mathrm{~Hz}$ ). The damping results are presented in Fig. 9 and are in line with the literature [38].

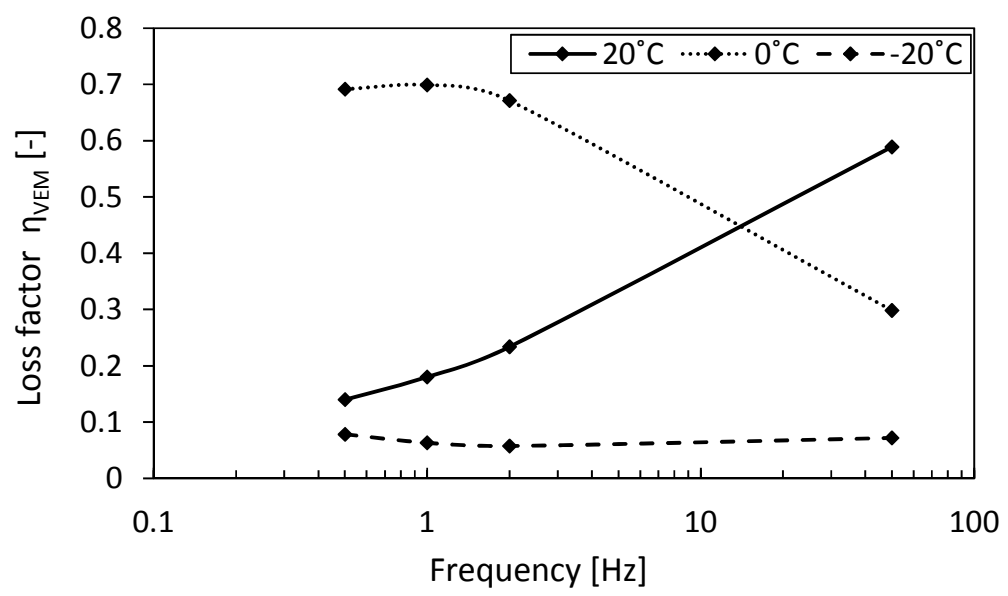

Figure 9: Frequency dependent loss factor of the VEM $\eta_{V E M}$ for $-20^{\circ} \mathrm{C}, 0^{\circ} \mathrm{C}$ and $20^{\circ} \mathrm{C}$.

As expected, the dynamic material properties of DYAD 601 show a strong frequency and temperature dependency, which is typical for VEM's. The maximum damping is observed at $0{ }^{\circ} \mathrm{C}$ and low frequencies up to $2 \mathrm{~Hz}$, verifying the proposed temperature range in the data sheet [25]. The glass transition temperature range is therefore assumed to be close to $0^{\circ} \mathrm{C}$ at low frequencies. An increase in frequency leads to a different behaviour of the loss factor depending on the temperature. While the damping decreases with increasing frequency at 
$0^{\circ} \mathrm{C}$, the damping increases at $20^{\circ} \mathrm{C}$ and remains constant at $-20^{\circ} \mathrm{C}$. The maximum damping capacity of the DYAD is therefore assumed to be between $0^{\circ} \mathrm{C}$ and $20^{\circ} \mathrm{C}$, as at higher frequencies the glass transition and therefore the peak damping shifts to higher temperatures [39].

In Fig. 10 the storage and loss moduli for DYAD 601 are presented for different temperatures and frequencies. An increase in frequency from $0.5 \mathrm{~Hz}$ to $50 \mathrm{~Hz}$ only slightly changes the storage modulus at $-20^{\circ} \mathrm{C}$ and $20^{\circ} \mathrm{C}$, whereas the storage modulus quadruples at $0^{\circ} \mathrm{C}$. Furthermore, the loss modulus at $0{ }^{\circ} \mathrm{C}$ is slightly higher compared to $-20^{\circ} \mathrm{C}$ and increases with increasing frequency. The glass transition temperature Tg is therefore assumed to be between $-20^{\circ} \mathrm{C}$ and $0^{\circ} \mathrm{C}$ for low frequencies, shifting towards $0{ }^{\circ} \mathrm{C}$ with higher frequencies

The observations are coherent with the literature, as $\mathrm{Tg}$ is always below the temperature of the peak damping

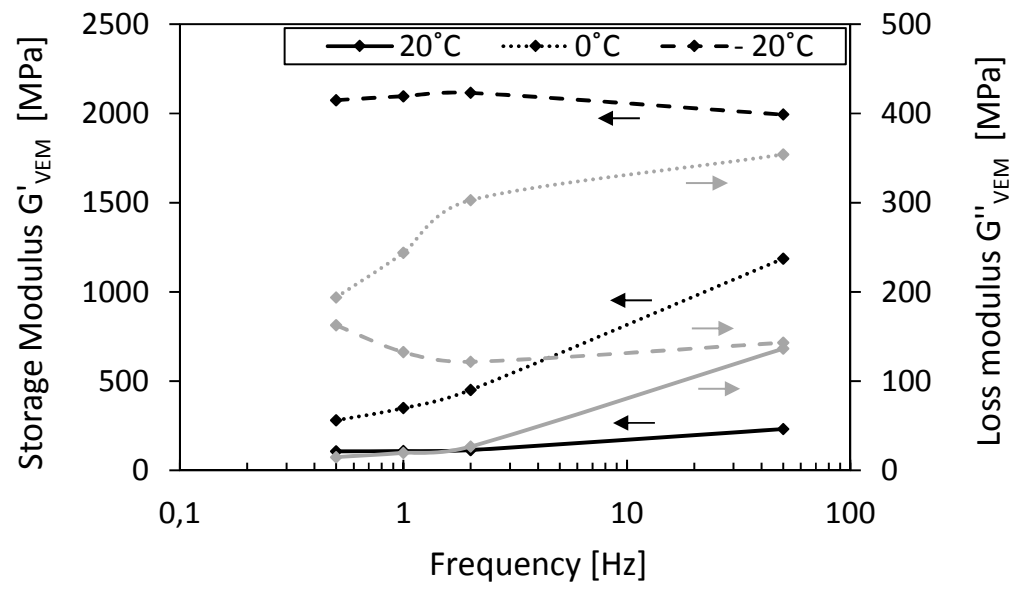

Figure 10: Frequency dependent storage and loss modulus of the VEM for $-20^{\circ} \mathrm{C}, 0{ }^{\circ} \mathrm{C}$ and $20^{\circ} \mathrm{C}$.

[34]. Based on the results above, the viscoelastic material properties of DYAD 601 may be approximated by

$$
\begin{aligned}
& G^{\prime}(f)=29.07 \ln (f)+111.93[\mathrm{GPa}], \\
& G^{\prime \prime}(f)=28.00 \ln (f)+22.03[\mathrm{GPa}],
\end{aligned}
$$

as a function of the frequency at $20^{\circ} \mathrm{C}$.

\subsubsection{UD-composite coupons}

The fibre direction dependent modal damping of GF-EP was investigated at room temperature using the VBT method for coupon specimens with five fibre directions $0^{\circ}, 30^{\circ}, 45^{\circ}, 60^{\circ}$ and $90^{\circ}$. The frequency dependency is evaluated by distributed measurements between $20 \mathrm{~Hz}$ and $60 \mathrm{~Hz}$, whereas the results at $20 \mathrm{~Hz}$ are based on a previous investigation [14].

The modal damping was determined at higher frequencies by gradually reducing the free length of the clamped composite coupons. The first 50 periods were considered for analysing the damping by Eq. (6) and (7). The fibre direction dependent damping properties for the five fibre directions at $20^{\circ} \mathrm{C}$ are presented in Fig. 11 with respect to frequencies in the range between $20 \mathrm{~Hz}$ and $60 \mathrm{~Hz}$.

A slight increase in the loss factor with frequency is observed for all investigated fibre directions. The trend and magnitude of the damping for GFRP is in accordance to the literature [40]. The direction dependent 


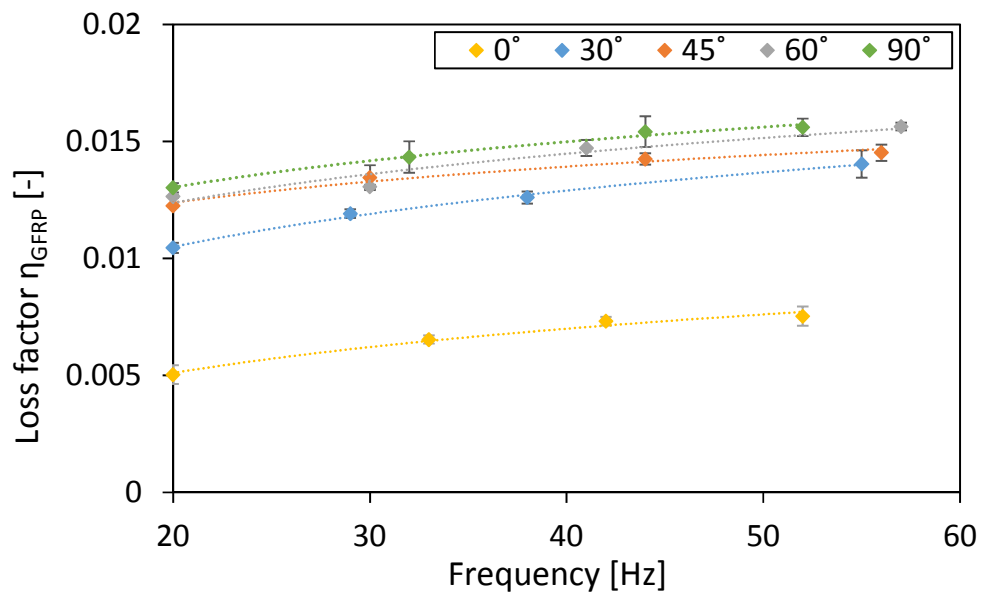

Figure 11: Fibre direction dependent damping properties of GF-EP for varying frequencies [VBT, $\left.20^{\circ} \mathrm{C}\right]$

Table 3: Fibre direction dependent modal damping properties $\eta_{11}, \eta_{22}$ and $\eta_{12}$ of GF-EP based on the AdamsBacon approach and VBT measurements at $20^{\circ} \mathrm{C}$ and $30 \mathrm{~Hz}, 40 \mathrm{~Hz}$ and $50 \mathrm{~Hz}$.

\begin{tabular}{|c|c|c|c|c|c|c|c|c|c|}
\hline \multirow{2}{*}{ Material } & \multicolumn{3}{|c|}{$30 \mathrm{~Hz}$} & \multicolumn{3}{|c|}{$40 \mathrm{~Hz}$} & \multicolumn{3}{|c|}{$50 \mathrm{~Hz}$} \\
\hline & $\eta_{11}[-]$ & $\eta_{22}[-]$ & $\eta_{12}[-]$ & $\eta_{11}[-]$ & $\eta_{22}[-]$ & $\eta_{12}[-]$ & $\eta_{11}[-]$ & $\eta_{22}[-]$ & $\eta_{12}[-]$ \\
\hline GF-EP & 0.0062 & 0.0142 & 0.0130 & 0.0070 & 0.0148 & 0.0139 & 0.0076 & 0.0155 & 0.0146 \\
\hline
\end{tabular}

modal damping $\eta_{11}, \eta_{22}$ and $\eta_{12}$ of a representative UD GF-EP layer was calculated based on the Adams-Bacon approach $[41,14]$.

The properties are presented in Tab. 3 for $30 \mathrm{~Hz}, 40 \mathrm{~Hz}$ and $50 \mathrm{~Hz}$, in order to provide damping data for the simulation of the generic composite cylinder under varying tip loads. The direction dependent modal damping properties of GF-EP at galloping relevant environmental conditions are presented in literature [14].

\subsection{Static and dynamic characterisation on structural level}

The modal damping of the cylindrical composite structure was investigated experimentally by the free decay method and compared numerically using the modal strain-energy method. Furthermore, the static bending stiffness of the eight composite cylinders with various cross-sectional designs was determined in order to understand the relation between the increasing outer geometry and the natural frequency of the first bending mode.

\subsubsection{Static structural testing}

In order to investigate the change in bending stiffness by applying various CLD treatments on cylindrical composite structures with a constant inner diameter of $D_{i}=79 \mathrm{~mm}$, quasi-static bending tests were conducted. In Fig. 12 the bending load-deflection curves of selected specimens are presented. 


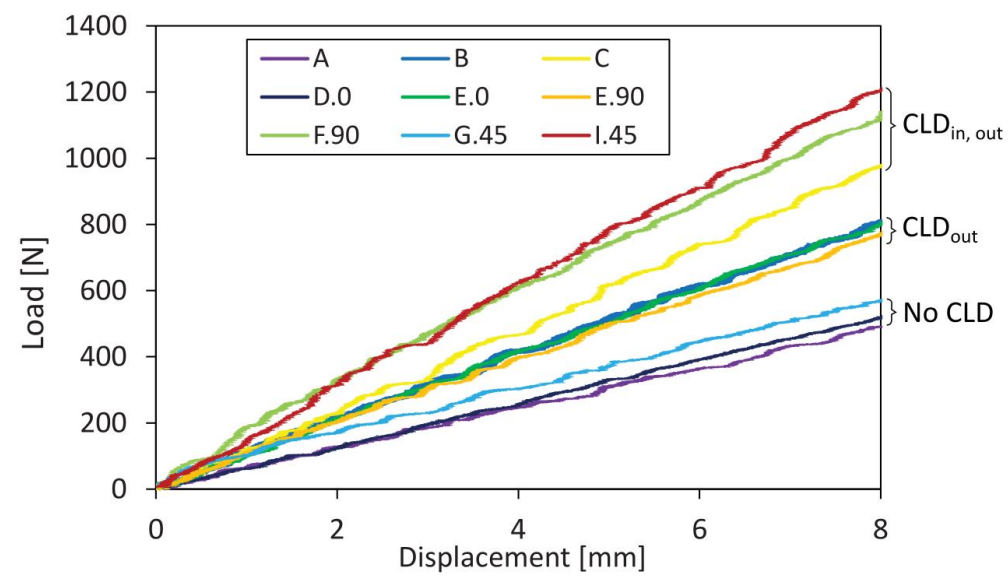

Figure 12: Static load-displacement curves for a selection of specimens with different cross-sectional designs.

The bending stiffness of all cross-sectional design concepts behaves linearly within the analysed range of deflection of approximately $0.8 \%$ of the free cylinder length. The noise-like pattern of each curve may be explained by stick-slip effects relative to the clamping fixture or the load introduction elements close to the tip of the cylinder. The presented curves may be assigned into three groups in order to fairly compare the effect of additionally implemented stiffening webs, as the application of constraining layers to the in- and outside, purely floating on the VEM, have a major impact on the bending stiffness: 1.) specimens without CLD treatment (concepts A, D and $G), 2$.) specimens with a CLD treatment only on the outside (concept B and E) and 3.) specimens with a CLD on the in- and outside (concept C, F and I).

The difference in bending stiffness between the groups originates mainly from the increase in wall thickness by the application of CLD treatments or the increase of diameter of the host structure (load carrying laminate) by adding a CLD treatment on the inside of the cylinder (concept B and C) (see Fig. 2).

The differences in bending stiffness within the groups may be explained by the presence of shear webs or the slight ovalization of the cross section (see section 3.4.2). The variation of the free vibration length of $960 \mathrm{~mm}$ within the range of $\pm 3 \mathrm{~mm}$ may also lead to a slight impact on the static bending stiffness.

However, the reference structure (design concept A) shows the lowest bending stiffness, followed by the concept D.0 and concept G.45. The slight increase is due to the vertical oriented shear web with its well suited fibre orientation of $\varphi= \pm 45^{\circ}$. The presence of two shear webs, inclined by $\pm 45^{\circ}$ to the loading direction (concept G.45), leads to a slightly higher bending stiffness compared to one shear web parallel to the loading direction (concept D.0).

The bending stiffness increases further by adding a circumferential CLD treatment on the outside (concept E.0, E.90 and B). A stiffening effect by an additional, vertical oriented shear web (concept E.0) is not observed at this magnitude of bending stiffness. However, the slight decrease in bending stiffness for design concept E.90 compared to the concepts B and E.0 may be due to its slight ovalized cross section. The differences in stiffness between concept C and F.90 are also assumed to be due to the ovalized cross section, resulting in a higher effective diameter when loading in the direction of $90^{\circ}$ (see Fig. 2). As already shown for concept G.45, two inclined shear webs with an inclination of $\pm 45^{\circ}$ to the loading direction lead to a further increase of bending 
stiffness (concept I.45).

\subsubsection{Dynamic structural testing}

The modal damping of the composite structure was determined by a free vibration test at room temperature. The test rig with a mounted I.45 specimen is shown in Fig. 13, superimposed by its equivalent numerical FE-model.

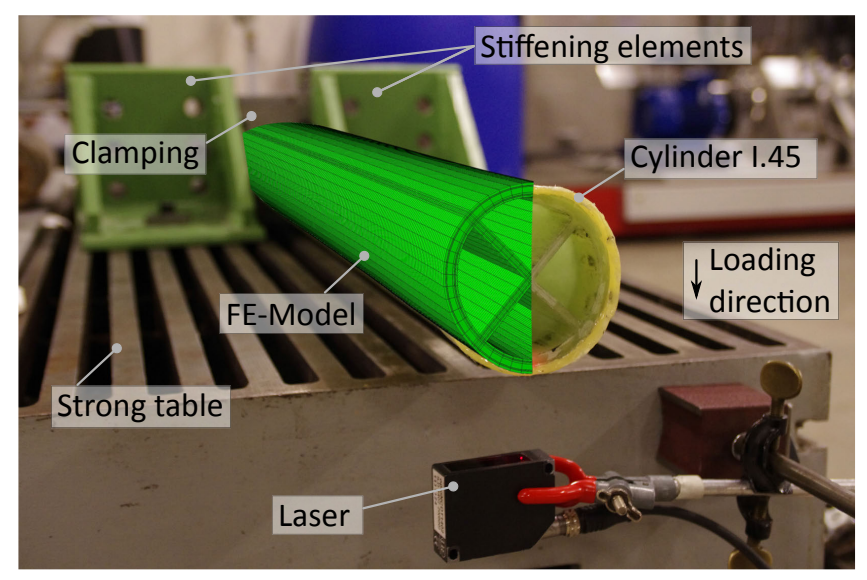

Figure 13: Test rig with clamped cylindrical specimen (design concept I.45).

The free vibration was initiated by an impulse in vertical direction, using a rubber block mounted on a bracket. The orientation of the shear webs was thereby adjusted with regard to the excitation direction for each specimen. It is assumed that the response signal is mainly related to the first activated bending mode. Therefore, an envelope may be exponentially fitted on the free decay curve of the vibrating composite structure, resulting in the damping ratio by Eq. (6). However, the first 10 periods were neglected in order for potentially activated higher modes to die out (see Fig. 14a and 14b).

In order to verify the dominance of the first flexural mode, a Fourier analysis of the experimental time-history was carried out for the cross-sectional concept A. As expected, the resulting frequency plot, shown in Fig. 15, verifies the dominance of first flexural mode at about $50 \mathrm{~Hz}$ and a neglectable peak at about $450 \mathrm{~Hz}$.

The natural frequencies of composite specimens with different cross-sectional designs were determined in order to evaluate the influence of additional CLD treatments. However, a quantitative comparison is not appropriate, as the diameter increases between the groups, each with a similar outer geometry (No CLD to CLD out to $\mathrm{CLD}_{\text {in }, \text { out }}$ ) (see section 6.2.1).

Therefore, the first natural frequencies were compared qualitatively for the different groups, supported by the stiffness-weight-ratio (see Fig. 16). The free specimen length of $l=960 \mathrm{~mm} \pm 3 \mathrm{~mm}$ was kept constant for all investigated composite structures. The first natural frequency varies with $f_{1}=50 \mathrm{~Hz} \pm 6 \mathrm{~Hz}$ only slightly for all investigated specimens. The increasing outer dimensions between group 'NoCLD' and 'CLD out', each represented by concept $\mathrm{A}$ and $\mathrm{B}$, is demonstrated by an increase in the stiffness-weight-ratio, respectively.

However, a clear increasing stiffness-weight-ratio also implies that the VEM damping layer is too stiff. The 

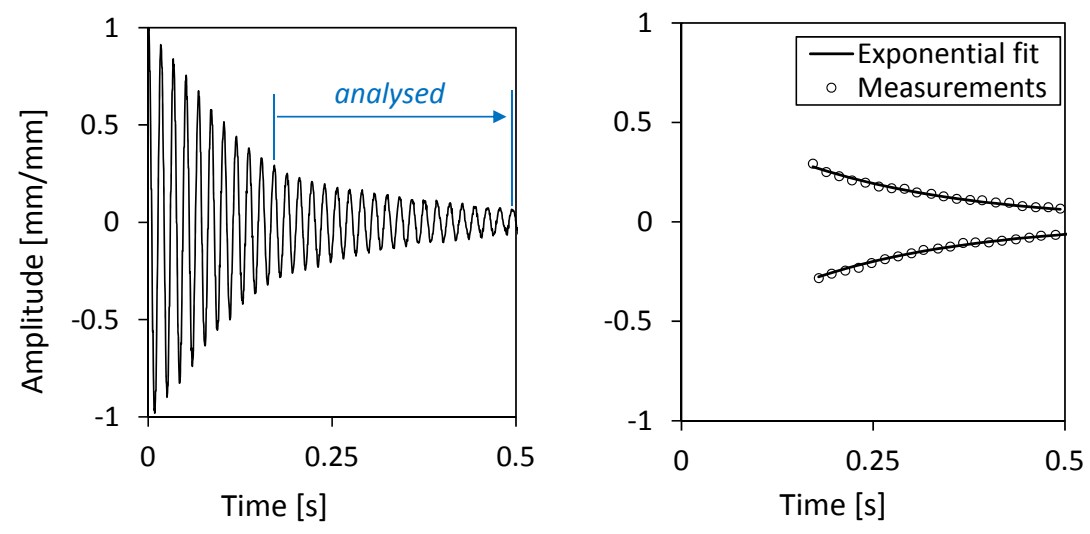

(a) Normalized free decay for (b) Comparison of measured data the analysed period range with its exponential fit in the range $P_{10}<P_{\text {analysed }}<P_{30}$. $\quad P_{\text {analysed }}$.

Figure 14: Normalized free decay (a) of a vibrating composite cylinder with the cross-sectional design concept $\mathrm{B}$, on which an exponential decay curve was fitted (b).

VEM simply transfers the shear stresses to the floating and stiff constraining layer and therefore unintentionally contributes to the structural stiffness, instead of deforming in shear. A reduction of the VEM shear stiffness is thereby assumed to enhance the shear deformation and thus the energy dissipation. A variation in the VEM stiffness will be discussed in more detail in section 6.2.3. However, the application of the CLD treatment to the inside of the cylinder (concepts B and $\mathrm{C}$ ) is verified to be less effective due to an unchanged stiffness-weightratio. Furthermore, the application of shear webs parallel to the loading direction is not an effective method to increase the stiffness with respect to weight, demonstrated by a decreased stiffness-weight-ratio (concept A vs. D.0 | B vs. E.0 | C vs. F.0). The purely cylindrical cross section is therefore the most effective with regard to

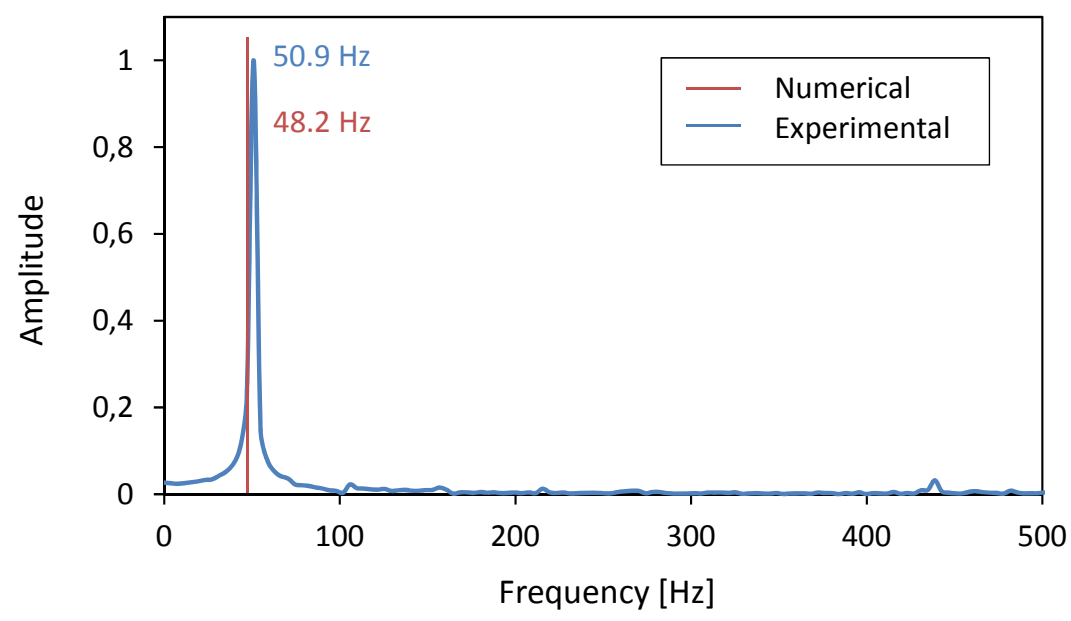

Figure 15: Results of the Fourier analysis with regard to the experimental time history of the cross-sectional concept A for the range $P_{10}<P_{\text {analysed }}<P_{30}$. 


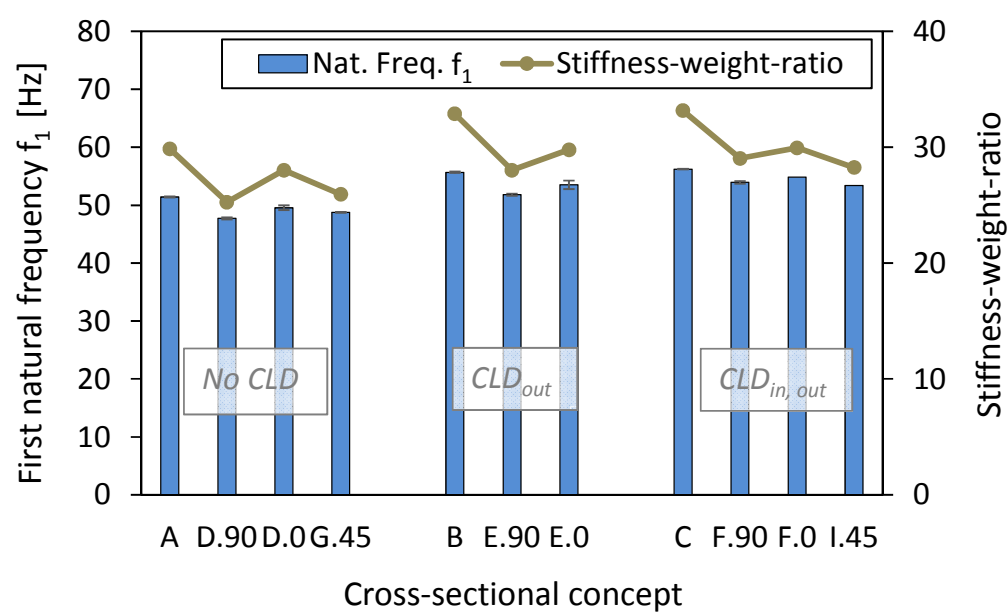

Figure 16: Results of the first natural frequency $f_{1}$ for all cross-sectional design concepts in relation to its stiffness-weight-ratio.

the investigated cross-section designs, represented by concept $\mathrm{A}, \mathrm{B}$ and $\mathrm{C}$ and its highest natural frequency $f_{1}$ within each group.

Shear webs with a $90^{\circ}$ orientation (concept D.90, E.90 and F.90) lead to lower natural frequencies compared to shear webs in $0^{\circ}$, due to the vanishing contribution to the structural stiffness but increase in weight. A shear web in $90^{\circ}$ may therefore only be used for the application of CLD treatments close to the neutral plane in order to increase the damping of a vibrating composite cylinder.

Although a considerable potential of the CLD treatment is assumed to be untapped due to the high VEM stiffness, the resulting damping is shown for all cross-sectional designs in Fig. 17.

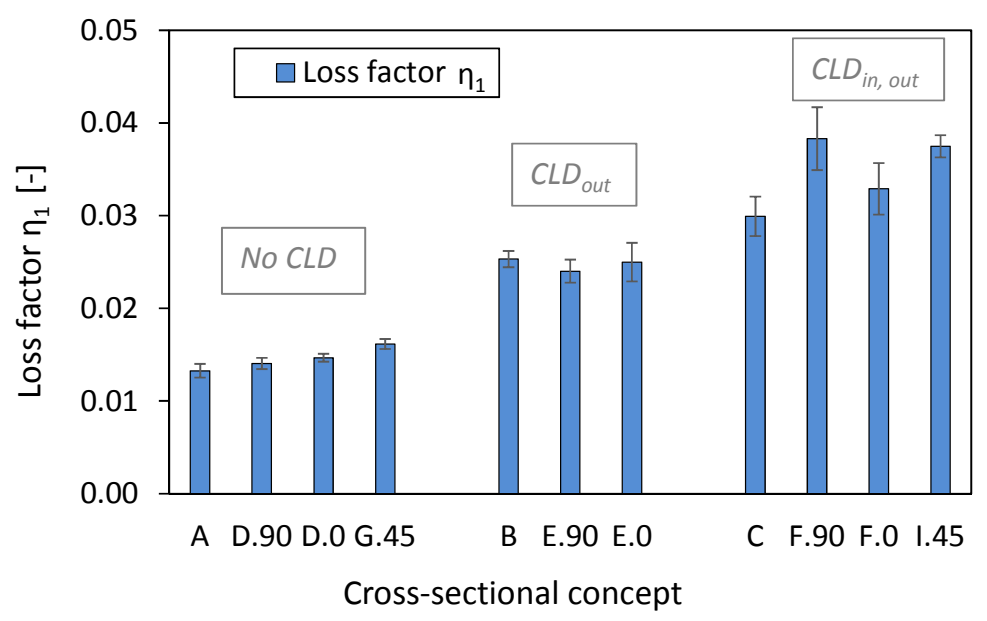

Figure 17: Results of the modal loss factor $\eta_{1}$ related to the first bending mode.

As expected, the damping of composite cylinders without CLD treatments (concept A, D and G) is significantly below the damping of specimens with a CLD treatment on the outside (concept B and E), followed by specimens with CLD treatments on the in- and outside (concept C, F and I). The reference design concept A exhibits 
thereby the lowest damping. In the group of specimens without VEM damping layers, a slight increase is observed for specimens with shear webs (design concepts D and G).

Furthermore, the specimen with two shear webs, inclined by $\pm 45^{\circ}$ to the loading direction (concept G.45), shows slightly higher damping compared to specimens with one shear web parallel to the loading direction (concept D.0). This may be explained by the fibre direction of $\varphi= \pm 45^{\circ}$ of the shear webs and its matrix dominated, high damping properties.

A significant increase in damping is achieved by introducing CLD treatments. An application on the outside of the cylinder (concept B and E) leads to an increase of ca. $90 \%$. A shear web parallel to the loading direction (concept E.0) has no effect on the loss factor at this level of damping, generated by a CLD treatment on the outside of the structure. The highest damping, compared to the reference concept A, is observed for specimens with CLD treatments on the in- and outside (concept C, F, and I), corresponding to the largest amount of applied VEM. The damping increases by ca. $130 \%$ for concept C and ca. $190 \%$ for concept F.90.

The specimen with the highly complex cross-sectional design I.45 leads to an increase of ca. $180 \%$. Only a slight increase in damping is observed for concept F.0 compared to C, as only a small portion of VEM is located within the neutral plane, experiencing shear, compared to F.90. As expected, the highest damping is observed for concept F.90, which represents the largest amount of VEM subjected to shear deformation: at the shear web close to the neutral plane and along the circumference, far away from the neutral axis.

It is expected that composite structures, which are composed of viscoelastic materials, show the same trend of frequency dependent behaviour as each individual material involved (see Fig. 9 and 11). Therefore, the modal damping of all cylindrical composite specimens was determined at three different frequencies by attaching tip masses. The results are plotted in Fig. 18.

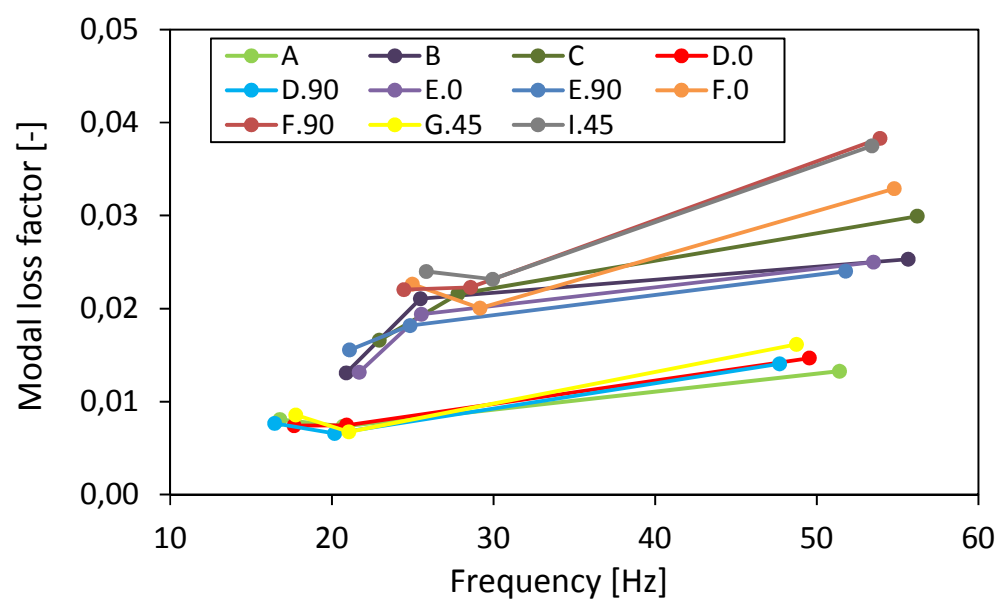

Figure 18: Variation of the test frequency for all cross-sectional design concepts at room temperature.

The same trend of frequency dependent damping is observed compared to the raw materials used for the cylindrical composite structure: GFRP and VEM. The damping decreases with decreasing frequencies. Furthermore, the significant damping enhancement by introducing CLD treatments is clearly demonstrated for a frequency range between approximately $20 \mathrm{~Hz}$ and $60 \mathrm{~Hz}$.

As the modal loss factor $\eta_{1}$ was determined for all investigated specimens at varying frequencies with $52 \mathrm{~Hz} \pm 5 \mathrm{~Hz}$ 
(see Fig. 16), the loss factors and natural frequencies were normalized by the results of the reference concept A in order to enable comparability. The ratio of normalized damping to the normalized frequency therefore describes an equivalent damping, which refers to the first natural frequency of concept A. The results are shown in Fig. 19.

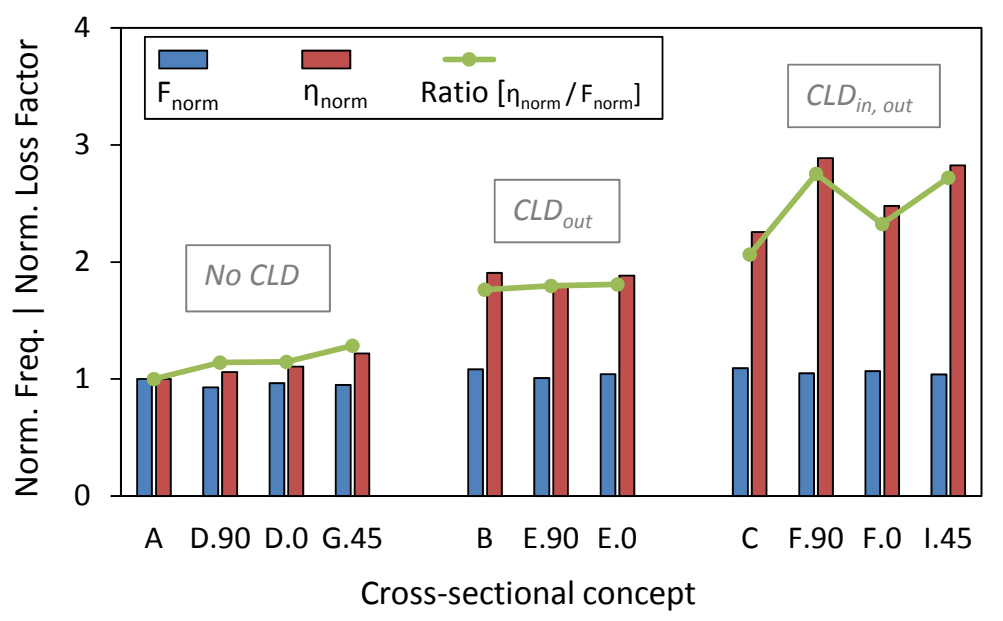

Figure 19: Results of the normalized frequency and loss factor (with respect to the reference design concept A) and its related damping-frequency-ratio.

The equivalent damping represents the damping behaviour at a frequency $f_{1_{A}}=51.4 \mathrm{~Hz}$ and therefore facilitates comparability between the specimens. Only slight changes in the trend are observed between the equivalent damping (Fig. 19) and the results of the first loss factor $\eta_{1}$ (Fig. 17). In general, the damping increases directly proportional to the amount of VEM used for the CLD treatment.

For specimens without CLD treatments, the damping slightly increases by adding shear webs with a fibre orientation of $\varphi= \pm 45^{\circ}$, as its matrix dominated damping values enhances the overall damping. As expected, the increase in number of shear webs from 1 to 2 leads to an increase in the equivalent damping (concept D.0 to G.45). However, this effect is hardly observed for specimens with a CLD treatment on the outside (concept B, E.90 and E.0) due the dominating effect of VEM. The equivalent damping increases even further when considering a CLD treatment to the in- and outside (concept C, F.90, F.0 and I.45). The highest damping is

Table 4: Increase in damping with regard to the reference design concept A or the representative design concept of each group A, B or C.

\begin{tabular}{|c|c|c|c|c|c|c|c|c|c|c|c|}
\hline Increase in & \multicolumn{11}{|c|}{ Cross-sectional design concept } \\
\hline damping [\%] & \multicolumn{4}{|c|}{ Group 'No CLD' } & \multicolumn{3}{|c|}{ Group 'CLD out' } & \multicolumn{4}{|c|}{ Group 'CLD ${ }_{\text {in }, \text { out }}$ ' } \\
\hline with respect to $\ldots$ & A & D.90 & D.0 & G. 45 & B & E.90 & E.0 & $\mathrm{C}$ & F.90 & F.0 & I. 45 \\
\hline$\ldots \mathrm{A}$ & Ref. & 142 & 147 & 284 & 76.2 & 79.7 & 81.0 & 106.3 & 175.3 & 132.6 & 172.0 \\
\hline$\ldots \mathrm{A}, \mathrm{B}$ or $\mathrm{C}$ & Ref. & & & & Ref. & 2.0 & 2.7 & Ref. & 33.4 & 12.7 & 31.8 \\
\hline
\end{tabular}


Table 5: Results of the numerical frequency analysis of the cross-sectional design concept A.

\begin{tabular}{ccccccccc}
\hline Mode & 1 & 2 & 3 & 4 & 5 & 6 & 7 & 8 \\
\hline Frequency [Hz] & 48.2 & 48.2 & 285.1 & 285.1 & 468.2 & 699.6 & 699.6 & 708.3 \\
\hline Mode type & \multicolumn{1}{c}{ Bending (out-of-plane) } & Torsion & Bending (in-plane) & Axial \\
\hline
\end{tabular}

therefore observed for concept F.90, demonstrating the potential of the additional CLD treatment close and in parallel to the neutral plane.

The percentage-wise increase of the damping is represented in Tab. 4, with regard to either the reference design concept $\mathrm{A}$ or the representative design concept of each group $\mathrm{A}, \mathrm{B}$ or $\mathrm{C}$.

\subsubsection{Comparison of numerical and experimental results}

The experimental results were used to verify the numerical model, which predicts the first natural frequency $f_{1}$ and the related modal damping $\eta_{1}$ of the cylindrical composite structures with varying cross-sectional design (see section 4). The experimental and numerical results of the first natural frequency are presented in Fig. 20. A good correlation of the experimental and numerical results of the first natural frequencies for all investigated cylinder concepts is observed with the trend of a slight under-prediction by the FEA. The consistency of the under-prediction indicates an inaccuracy related to the material properties or the manufacturing process. The material properties, used for the numerical analysis, may be too conservative although the same GF and resin were utilized (see section 3.3).

Another source of error may be related to the manufacturing process: constant change of fibre direction by a few degrees or a slightly different layer thickness may result in a lower predicted natural frequency.

In order to verify the experimental results of the Fourier analysis, demonstrating the dominance of the first flexural mode, a numerical frequency analysis was carried out (see Tab. 5). As expected, the numerically

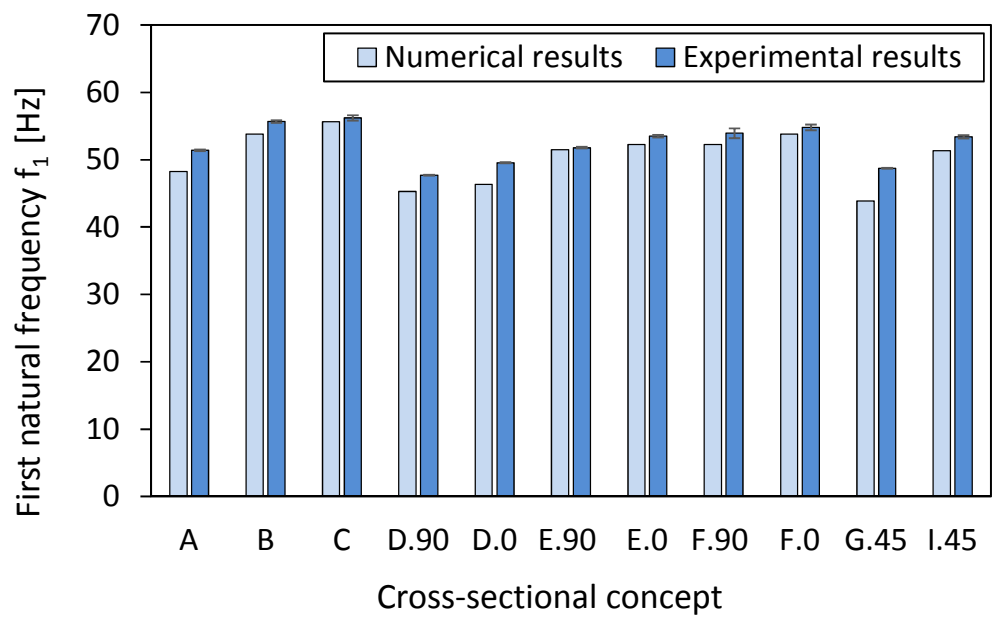

Figure 20: Numerical and experimental results of the first natural frequencies. 
and experimentally determined natural frequencies of the first flexural mode coincide with an error of about $5 \%$, demonstrated for the cross-sectional design concept A (see Fig. 15). The observed peak at about $450 \mathrm{~Hz}$ is associated with the first torsional mode. However, the intensity is very low, so that any influence may be neglected. The comparison of the experimental and numerical damping is based on the presented loss factors in Fig. 21. The numerical predicted loss factors are considerably lower than the experimental values. However, the same trend of the damping is captured by the simulation for all cross-sectional design concepts, although the differences increase disproportionally with the application of VEM damping layers (concept B, C, E, F and I). The predicted damping for concepts without CLD treatments are maximum $39 \%$ lower than the experimental results (concept G.45), compared to maximum $64 \%$ for concepts with CLD treatments (concept F.90). The increased mismatch may be attributed to a much softer clamping area, caused by the continuous VEM, compared to concepts without CLD.

Although metallic inserts were used to allow each end section to be compressed and clamped, a continuous VEM layer can deform and creep in axial direction of the specimen, leading to a reduced clamping pressure and therefore to an increased friction damping. These clamping effects, substantially increased by an applied VEM, lead to higher experimental damping values, which are not captured in the numerical model.

Furthermore, a variation in the tolerance of the lathed end section of the composite cylinders may lead to different clamping conditions and therefore to a different contribution of friction damping. An enhanced specimen stiffness may also result in an increase in clamping effects and therefore in damping. The horizontal displacement of the metallic clamping were measured, while specimens with different bending stiffness were loaded: a maximum displacement of $0.005 \mathrm{~mm}$ or $0.06 \mathrm{~mm}$ was observed at a bending load of $0.85 \mathrm{kN}$ or $1.6 \mathrm{kN}$ for concepts A or I, respectively. This leads to an enhanced friction damping relative to the strong table and therefore an increase in the measured decay.

A correction factor may be applied in further investigations to account for the discrepancies in the clamping area mentioned above, causing differences between the experimentally and numerically determined loss factor. Several displacement measurements at various locations in the clamping area may therefore be considered in

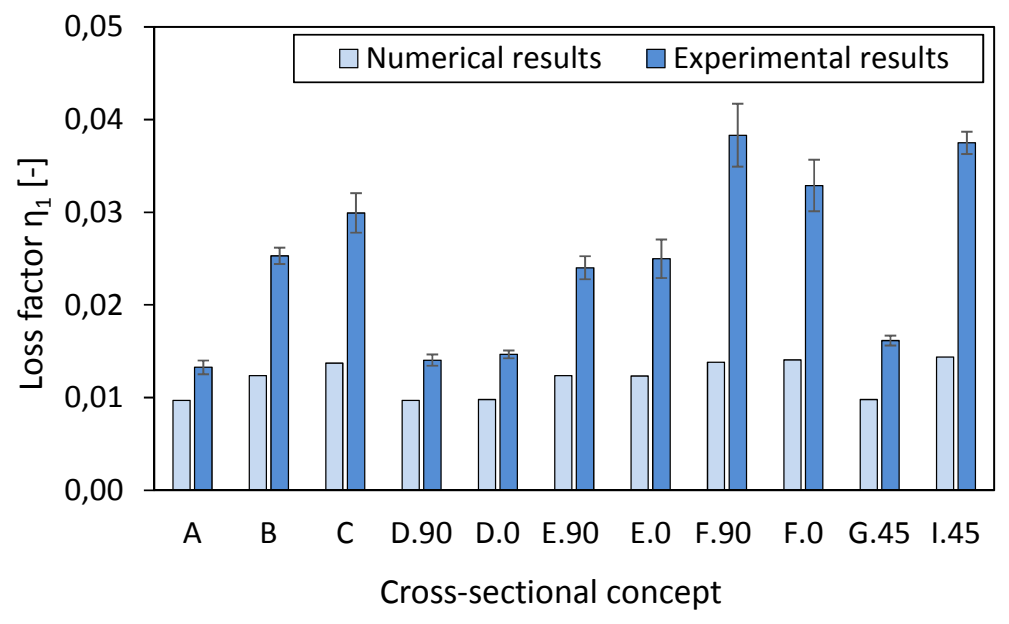

Figure 21: Numerical and experimental results of the modal loss factor related to the first bending mode. 
order to understand the phenomenon and to determine the relative displacement between the points of interest. However, the highest damping was observed for the specimen with the cross-sectional design concept F.90. This result is expected, since a large area of VEM is well located where the largest shear stresses appear (see section 3.2). As mentioned in section 6.2.2, the VEM DYAD 601 is seemingly too stiff in order to allow sufficient shear deformations. Instead, the occurring stresses may simply be transferred to the constraining layer, leading to an increase in structural stiffness but no damping. Therefore, the effect of the VEM stiffness on the modal damping $\eta_{1}$ and first natural frequency $f_{1}$ was numerically investigated for the design concept F.0 and F.90 using the modal strain-energy method. A decrease of the storage modulus $G^{\prime}$, while keeping the loss factor $\eta$ constant, will relatively adjust the loss modulus $G^{\prime \prime}$ by

$$
\eta=\frac{G^{\prime \prime}}{G^{\prime}}
$$

The results are presented in Fig. 22.

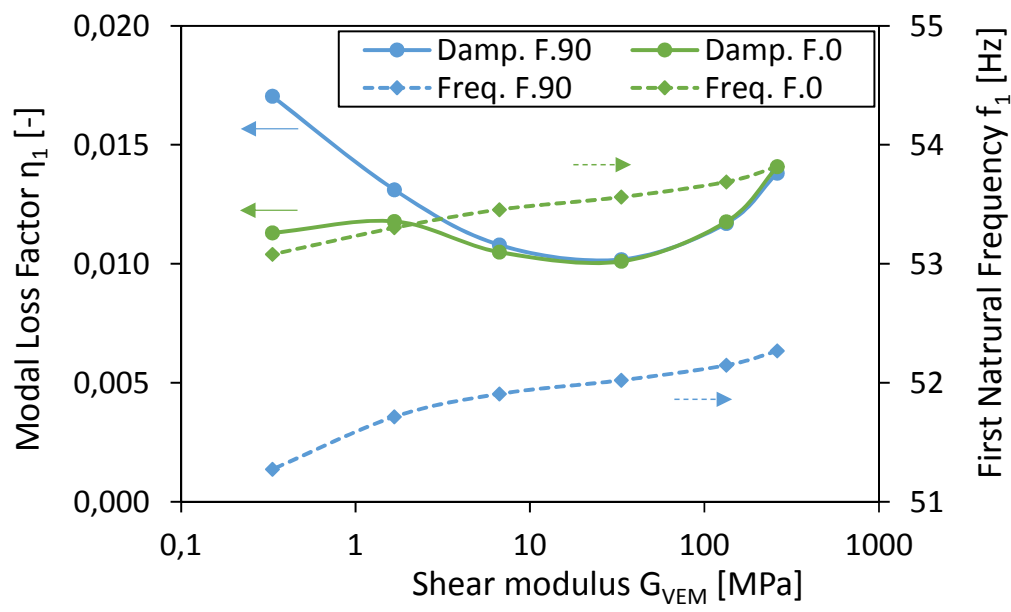

Figure 22: Effect of the shear modulus of the VEM on the first natural frequency $f_{1}$ and the related structural modal loss factor $\eta_{1}$ for the concepts F.0 and F.90.

As expected, the reduction of the VEM stiffness results in the same constant decrease of the first natural frequency for both concepts. The initial decrease in loss factor is unexpected, but may be explained by the non-appearance of shear deformation within the VEM, located on the circumference. The trend is the same for both concepts, where the only difference is the orientation of the shear web.

However, the modal loss factor increases for both concepts below the shear modulus $G_{V e m}$ of about $30 \mathrm{MPa}$, but slightly decreases with a shear modulus lower than $1 \mathrm{MPa}$ only for concept F.0. In contrast, the loss factor for concept F.90 continuously increases and exceeds its initial value of $\eta_{1}=0.0138$. The shear deformed VEM is plotted in the x,z plane in Fig. 23 for the concept F.90, when a shear modulus of $G=0.33 \mathrm{MPa}$ was used. The shear deformation of the VEM is equally distributed between the top, bottom and middle section, close to the neutral plane of the composite cylinder. This is expected as the four individual composite sections (1x Host structure, 2x inner CL, 1x outer CL), only coupled by the VEM, deform the same way as the load carrying host structure. The deformation plot verifies the higher loss factor compared to the concept F.0 with its shear web 


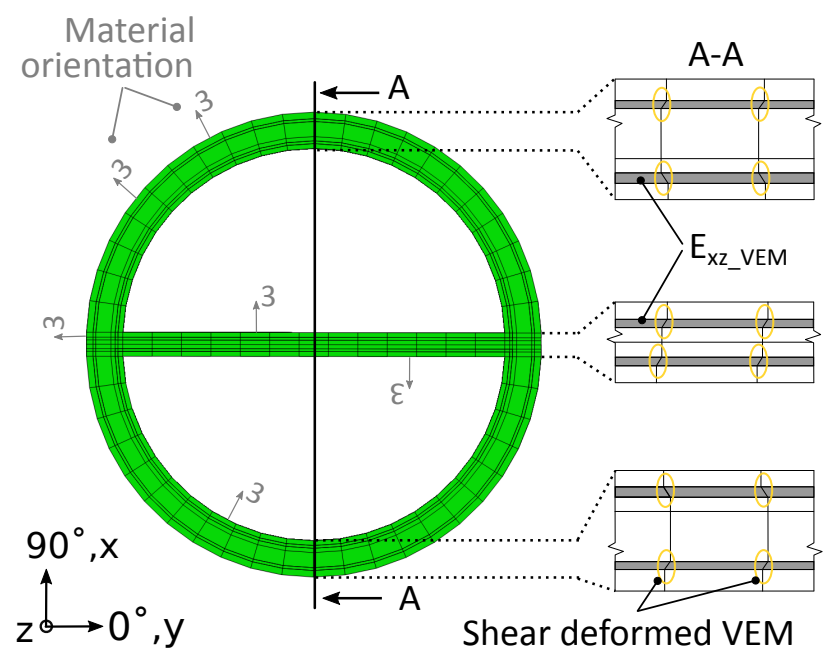

Figure 23: Numerical model of concept F.90 (vibrating in $90^{\circ}$ ) with its shear deformed VEM layers $\left(\mathrm{E}_{x z}\right)$.

oriented perpendicular to the neutral plane. The efficiency of a CLD treatment within the neutral plane has hereby been demonstrated successfully.

\section{Conclusion}

The present paper provides a method for the design of highly damped cylindrical composite structures under dynamic loading with passive CLD treatments, which can be used as sound basis for the design of the next generation of composite power pylon arms. The enhanced damping design is demonstrated by the experimental and numerical investigation of various cross-sectional design concepts, which differ in their complexity and weight. Furthermore, the manufacturing of generic composite cylinders by filament winding, the experimental modal analysis and the determination of the modal damping is thoroughly described.

A numerical damping model based on the modal strain-energy method finally confirms the trend of the experimental results with regard to the first natural frequency $f_{1}$ and the related modal loss factor $\eta_{1}$. Depending on the design requirements with respect to stiffness and weight, different levels of damping can be achieved in relation to cost and manufacturing capabilities.

The application of circumferential CLD treatments lead to a considerable increase of weight and wall thickness, while keeping the cross-sectional complexity constant. In contrast, shear webs with or without CLD treatments lead to an increase of the cross-sectional complexity, while keeping the change in stiffness and mass low. The maximum damping is achieved for the cross-sectional design concept F.90 with its high complexity and weight. However, a CLD treatment close to the neutral plane of the cylindrical composite structure is found to significantly increase the modal damping. A low stiffness of the VEM is thereby of crucial importance for a maximum shear deformation and damping. The main conclusions are drawn as follows:

- The damping of cylindrical composite structures can be enhanced by integrating shear webs (max. $+28 \%$ ) without applying CLD treatments. The complexity of the cross section thereby increases directly proportional, causing extra costs and effort during manufacturing. 
- The application of circumferential CLD treatments leads to an increase in damping of max. $106.3 \%$ (concept C) compared to the reference design concept A.

- An additional increase in damping is observed by max. 33\% (concept $\mathrm{C}$ to concept F.90), when applying CLD treatments in parallel and close to the neutral plane.

- The damping prediction of clamped composite cylinders, using the modal strain-energy method, leads partly to large deviations depending on the amount of applied VEM, due to different clamping conditions. The damping of specimens without CLD treatments can be predicted with deviations of max. $39 \%$, due to the disregard of friction damping in the clamping zone.

\section{Acknowledgement}

Thanks to Prof. M. Gude and Prof. N. Modler from the Institute of Lightweight Engineering and Polymer Technology of TU Dresden for their kind cooperation in manufacturing the cylindrical specimens. The authors are also indebted to The Soundcoat Company, providing the viscoelastic material for the vibrational tests.

\section{Declaration of conflicting interests}

The author(s) declared no potential conflicts of interest with respect to the research, authorship and/or publication of this article.

\section{Funding}

The author(s) disclosed receipt of the following financial support for the research, authorship and/or publication of this article: This research is supported by Innovationsfonden Denmark via the project Power Pylons of the Future $(\mathrm{PoPyFu})$ in collaboration with Bystrup and Tuco Marine ApS, which are gratefully acknowledged.

\section{References}

[1] Yang F, Yang J, Zhang Z, Xing H (2012) Dynamic Simulation on a Broken Test of Conductors. Procedia Engineering, International Conference on Advances in Computational Modeling and Simulation 31: 435440.

[2] Dang HX, Yang FL, L XM, Yang JB (2012) Galloping Characteristics of Conductor Accreted with CrescentShaped Ice. Applied Mechanics and Materials 226-228: 158-161.

[3] Hujare PP, Sahasrabudhe AD (2014) Experimental Investigation of Damping Performance of Viscoelastic Material Using Constrained Layer Damping Treatment. Procedia Materials Science, International conference on Advances in Manufacturing and Materials Engineering, Kuala Lumpur, 2014 5: 726-733.

[4] Trindade MA (2011) Experimental analysis of active-passive vibration control using viscoelastic materials and extension and shear piezoelectric actuators. Journal of Vibration and Control 17: 917-929

[5] Sasikumar KSK (2015) Vibration control of Beam with Composite Constrained Layer Treatment. International Journal of Latest Trends in Engineering and Technology 5: 176-184 
[6] Fotsing ER, Sola M, Ross A, Ruiz E (2012) Lightweight damping of composite sandwich beams: Experimental analysis. Journal of composite materials 47: 1501-1511

[7] Gallimore CA (2006) Passive Viscoelastic Constrained Layer Damping Application for a Small Aircraft Landing Gear System. Master thesis Virginia Polytechnic Institute and State University, 30.09.2008

[8] Ruzicka J (1961) Damping Structural Resonances Using Viscoelastic Shear-Damping Mechanisms: Part IDesign Configurations. Journal of Engineering for Industry 83: 403-413

[9] March ER, Hale LC (1998) Damping of Flexural Waves With Imbedded Viscoelastic Materials. Journal of Vibration and Acoustics 120: 188-193

[10] Huang CY, Tsai JL (2015) Characterizing vibration damping response of composite laminates containing silica nanoparticles and rubber particles. Journal of Composite Materials 49: 545-557

[11] Zhang SH, Chen HL (2006) A study on the damping characteristics of laminated composites with integral viscoelastic layers. Composite Structures 74: 63-69

[12] Wollmann T, Modler N, Dannemann M, Langkamp A, Nitschke S, Filippatos A (2017) Design and testing of composite compressor blades with focus on the vibration behaviour. Composites Part A: Applied Science and Manufacturing 92: 183-189

[13] Filippatos A, Dannemann M, Wohlfahrt D, Modler N (2016) Design of highly damped fibre-reinforced lightweight mast for automated storage systems in logistics. In Proceedings of the 23nd International Congress on Sound and Vibration ICSV 10.-14.July 2016, Athens

[14] Kliem M, Rueppel M, Høgsberg J, Berggreen C (2017) Damping properties of Nanoclay modified Glass and Aramid composites at low temperature and low frequencies. submitted 2017.

[15] Skouboe H (2017) Power pylon of the Future, BYSTRUP Design, E-mail: hs@bystrup.dk 16.11.2017.

[16] DIN EN 50341-1:2013-11 (2013) Overhead electrical lines exceeding AC 1 kV - Part 1: General requirements - Common specifications. Beuth Verlag 2013-11

[17] Trindade MA, Benjeddou A (2002) Hybrid Active-Passive Damping Treatments Using Viscoelastic and Piezoelectric Materials: Review and Assessment. Journal of Vibration and Control 8: 699-745. $10.1177 / 1077546029186$

[18] Klein B (2013) Leichtbau-Konstruktion: Berechnungsgrundlagen und Gestaltung . Springer Vieweg 10th edition

[19] Mengjin W (1990) Conductor Galloping and Control Measures. High Voltage Engineering 4: 1-22

[20] Moreira RAS, Rodrigues JD (2006) Partial Constrained Viscoelastic Damping Treatment of Structures: A Modal Strain Energy Approach. International Journal of Structural Stability and Dynamics 6: 397-411.

[21] Cortes F, Elejabarrieta MJ (2008) Structural vibration of flexural beams with thick unconstrained layer damping. International Journal of Solids and Structures 45: 5805-5813.

[22] Dannemann M (2012) Zur vibroakustischen Auslegung von Faserverbund-Leichtbaustrukturen. Dissertation Technische Universitaet Dresden, 2012.

[23] Gurung CB, Yamaguchi H, Yukino T (2003) Identification and Characterization of Galloping of Tsuruga Test Line Based on Multi-Channel Modal Analysis of Field Data. Journal of Wind Engineering and Industrial Aerodynamics 91: 903-924. 
[24] Kliem M, Høgsberg J, Wang Q, Dannemann M (2017) Characterization of clay-modified thermoset polymers under various environmental conditions for the use in high-voltage power pylons. Advances in Mechanical Engineering 9: 1-16.

[25] Soundcoat (2017) Data sheet of damping products. Material data sheet Retrieved from http://www.soundcoat.com/soundcoatdamping.pdf

[26] Lin W (2016) Creation and Evaluation of Polymer/Multiwall Carbon Nanotube Films for Structural Vibration Control and Strain Sensing Properties. Dissertation Florida International University, 2016. 10.25148/etd.FIDC001208

[27] Pai R, Lumsdaine A, Parsons M (2004) Design and Fabrication of Optimal Constrained Layer Damping Topologies. Proceedings Volume 5386, Smart Structures and Materials: Damping and Isolation 2004, doi: $10.1117 / 12.540065$

[28] Peters S (2011) Composite Filament Winding. ASM International 1st Edition.

[29] Skinner ML (2006) Trends, advances and innovations in filament winding. Reinforced Plastics 50: 28-33.

[30] Ungar EE, Kerwin M (1962) Loss factors of viscoelastic systems in terms of energy concepts. The Journal of the Acoustical Society of America 34: 954.

[31] ABAQUS (2017) ABAQUS Documentation. Dassault Systmes Providence, RI, USA.

[32] Qi X, Zhao X, Rose JL (2010) Ultrasonic guided wave simulation toolbox development for damage detection in composites. AIP Conference Proceedings 1211, 1095, doi.org/10.1063/1.3362163

[33] Kliem M (2017) Data for: Damping investigation of cylindrical composite structures with enhanced damping properties. Mendeley Data doi:10.17632/jxy3m76dg5.1

[34] Ehrenstein GW, Riedel G, Trawiel P (1998) Praxis der Thermischen Analyse von Kunststoffen. Hanser-Verlag, Muenchen, Wien.

[35] Gohl W, Spies KH (2003) Elastomere Dicht- und Konstruktionswerkstoffe: Gummitechnik, Richtlinien und Anwendungsbeispiele für Konstruktion und Praxis. Expert Verlag, 5th edition.

[36] Melo JDD, Radford DW (2005) Time and temperature dependence of the viscoelastic properties of CFRP by dynamic mechanical analysis. Composite Structures 70: 240-253.

[37] Beards CF (1996) Engineering Vibration Analysis with Application to Control Systems. Wiley - Technology and Engineering, 1st edition.

[38] Leibolt MF (2009) Noise control of an acoustic cavity coupled with a vibrating plate treated with a spatially varying constrained viscoelastic layer. Dissertation University of Maryland, 2009.

[39] Turi EA (1997) Thermal Characterization of Polymeric Materials. Academic Press, Brooklyn, New York, 2nd edition, P.529

[40] Berthelot JM, Sefrani Y (2004) Damping analysis of unidirectional glass and Kevlar fibre composites. Composites Science and Technology 64: 1261-1278

[41] Adams RD, Bacon DGC (1973) Effect of Fibre Orientation and Laminate Geometry on the Dynamic Properties of CFRP. Journal of Composite Materials 7: 402-428. 